Check for updates

Cite this: Mater. Chem. Front. 2020, 4, 750

Received 24th November 2019 Accepted 27th December 2019

DOI: 10.1039/c9qm00717b

rsc.li/frontiers-materials

\section{Bioinspired by cell membranes: functional polymeric materials for biomedical applications}

\author{
Xingyu Chen (D) *ab and Jianshu Li (D) *b
}

\begin{abstract}
The delicate compositions, structures, and functions of natural cell membranes provide ideal prototypes for the development of functional biomedical polymers. First, the cell membranes, e.g., the red blood cell membrane, can be directly utilized to coat the functional polymeric materials, achieving an excellent biocompatibility and long-term circulation in blood. Second, the lipids (particularly the phospholipids) and glycosylated molecules on the cell membranes help the design of anti-fouling and biocompatible biomaterials, which may also have high affinities to some specific molecules after a secondary modification. An interesting choline phosphate with the reverse order of phosphate choline in the cell membrane will be specifically discussed here. Third, the transmembrane/peripheral proteins and the channel structure of the cell membrane can also be used as prototypes of biomaterials with various functions, such as the recognition, separation, immobilization, and capture of biomolecules. This review describes such cell membrane bioinspired functional polymers for a variety of biomedical applications including drug/gene delivery, tissue engineering, implant materials, and molecular recognition and diagnosis. The structure-function relationships of these polymeric materials are discussed in detail. Finally, the challenges associated with these cell membrane bioinspired polymeric biomaterials are summarized.
\end{abstract}

\section{Introduction}

Polymeric materials have been widely applied in the biomedical field such as in dental/bone materials, implants, wound dressing, prosthetic materials, drug carriers, and tissue engineering scaffolds, owing to their desired mechanical and physical properties,

\footnotetext{
${ }^{a}$ College of Medicine, Southwest Jiaotong University, Chengdu, 610003, China. E-mail: chenxy@swjtu.edu.cn

${ }^{b}$ College of Polymer Science and Engineering, State Key Laboratory of Polymer Materials Engineering, Sichuan University, Chengdu 610065, P. R. China. E-mail: jianshu_li@scu.edu.cn
}

manufacturability into various shapes, sterilizing capability, and ease of modification with multiple functionalities, etc. ${ }^{1-9}$ Currently, the development of biomedical materials demands extremely high standards regarding their biocompatibility, functionality, and bioactivity. ${ }^{10-15}$ Researchers have attempted to partially or simultaneously fulfill these requirements using numerous strategies, among which biomimetic or bioinspired methods have shown the best potential because the molecules, structures, and systems in living organisms exhibit nature-based time-tested strategies for achieving attractive material properties. ${ }^{16-23}$

Based on an increasing fundamental understanding of the synthesis, self-assembly, and hierarchical structure of natural

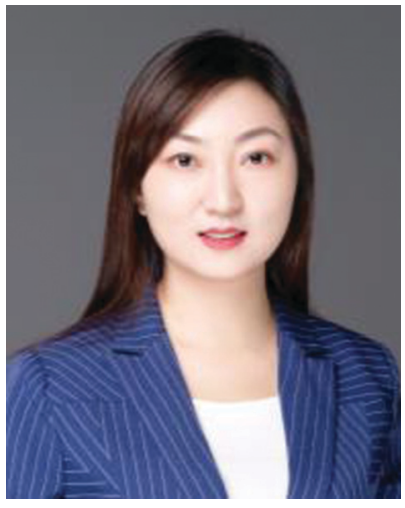

Xingyu Chen
Dr Xingyu Chen obtained her PhD (2015, Mater. Sci.) from Sichuan University. She is now an assistant professor at the College of Medicine, Southwest Jiaotong University. Her research focuses on the development of biomedical polymeric materials bioinspired from cell membranes.

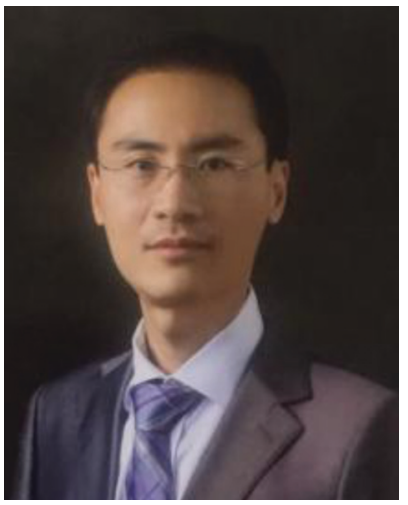

Jianshu Li
Dr Jianshu Li received his $B E$ (1999, Polym. Sci. Eng.) and $M E$ (2002, Biomed. Eng.) degrees from Sichuan University, China. He then obtained his PhD (2006, Chem. Eng.) from University of New Brunswick, Canada. He is now a full professor at the College of Polymer Science and Engineering, Sichuan University. His group consistently develops advanced functional polymeric materials for biomedical applications. 
living organisms, interdisciplinary bioinspired materials have been developed with numerous beneficial properties for various biomedical applications. ${ }^{24-32}$ For instance, biomineralization is a typical prototype used for bioinspiration, and is a biomoleculeguided process for producing minerals in algae, invertebrates, and vertebrates. Thus, numerous bioinspired strategies have been explored to prepare hierarchically functional biomaterials by controlling the growth of the inorganic phase through the regulation of biomolecules or their analogues. These biomineralized materials have been successfully utilized for dental/bone materials, drug delivery, and disease diagnosis, among other uses. ${ }^{33-36}$ Meanwhile, many other bioinspired prototypes, e.g., extracellular matrices, plants, insects, and mussel-proteins, have also been widely investigated for the development of functional polymers with tailorable chemical compositions and structures for biomedical applications. ${ }^{37-44}$

Cell membranes are a nanostructured molecular assembly and have become one of the most ideal prototypes for bioinspired polymeric biomaterials. The main reason for this is that the interaction at the cell-material level plays an important role in the biocompatibility and biofunctionality of biomaterials, and this interaction mainly takes place through the chemical components and structure of the cell membranes. It is well known that cell membranes are mainly composed of membrane lipids, ${ }^{45}$ glycoproteins, ${ }^{46}$ transmembrane proteins, and peripheral proteins. $^{47}$ They play different physiological roles in living organisms. For example, the amphipathic phospholipid bilayer can separate the intracellular components from the extracellular environment, and its zwitterionic phosphate choline component has well-known anti-fouling and anti-thrombogenic properties. Meanwhile, the hydrated glycocalyx located on the outside of the cell surface also prevents the adsorption of undesirable nonspecific proteins, whereas its main function is directing various specific molecular recognition processes. Thus, the zwitterionization and glycosylation strategies bioinspired by cell membranes can be utilized to prepare a variety of biocompatible and anti-fouling polymeric materials. At the surfaces of such materials, nonspecific protein adsorption is largely suppressed, and thus they can form a general platform for secondary decoration to obtain further useful functions such as molecular recognition, diagnosis, bioimaging, separation, and cell culturing, which have wide applications in the biomedical field.

It should be noted that in this review, the functional biomedical polymers bioinspired by cell membranes have several aspects: (1) the polymers themselves are directly bioinspired by cell membranes, e.g., phospholipid polymers; ${ }^{48}$ (2) the chemical components do not exist on the cell membrane, but interact with the components on cell membranes, e.g., choline phosphate based biomedical polymers; ${ }^{49-51}$ (3) the biomedical polymers are bioinspired from the structure/function of cell membranes, e.g., polymeric membranes with inserted natural or artificial channels; ${ }^{47,52}$ (4) the functional biomedical polymers are coated by cell membranes (e.g., red blood cell membrane ${ }^{53}$ ) or other cell membrane bioinspired units (e.g., glycocalyx $\left.{ }^{46}\right)$. Although some strategies inspired by the cell membrane have been separately reviewed before, such as

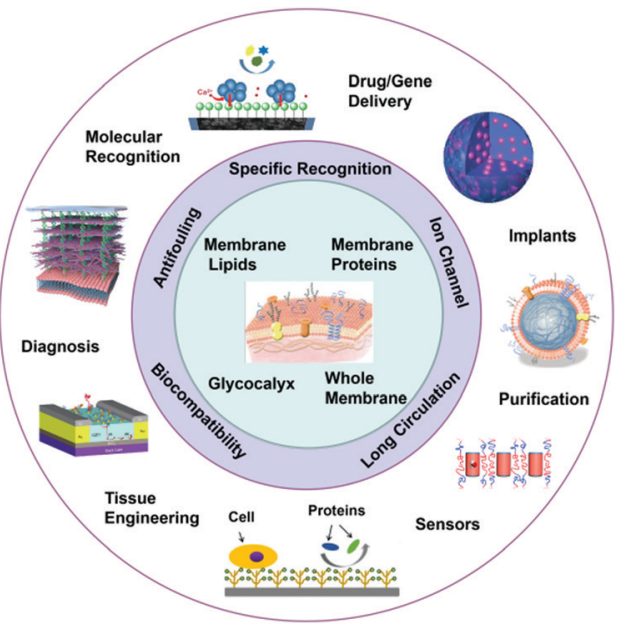

Fig. 1 General overview of the natural prototypes, structure-property relationship, and extensive biomedical applications of cell membrane bioinspired polymeric materials. Components reproduced with copyright permissions cited in Fig. 3, 7, 9, 11, 13, 14 and 17

phospholipid polymers based bioinspired interface, ${ }^{48}$ biomimetic glycosylated membranes ${ }^{46,54}$ and membrane protein inserted materials, ${ }^{47}$ and other reviews have focused on specific bioinspired materials, e.g., bioinspired coatings and membranes, ${ }^{27,54}$ this review focuses on those models that the cell membrane can provide to the design of bioinspired polymers and their various biomedical applications (Fig. 1). The design rationality, structure-property relationship, and challenges of these cell membrane bioinspired biomedical polymers are specifically discussed. Meanwhile, although there are quite a few excellent related studies on 'artificial cells' for fundamental research and biomedical applications, ${ }^{5-58}$ they are not discussed in this specific review.

\section{Cell membrane: Ideal prototype for bioinspired materials}

A human body has a total membrane area of approximately $10^{7} \mathrm{~m}^{2}$ of as calculated based on $\sim 10^{14}$ cells and a $\sim 63000 \mu \mathrm{m}^{2}$ membrane area per cell. ${ }^{59}$ It is well known that cell membranes are a nanostructured molecular assembly, and are mainly composed of membrane lipids, glycoproteins, glycolipids, transmembrane proteins, and peripheral proteins. In general, many characteristics of cell membranes, such as the chemical components, shape, membrane channels, physiological receptors, and their various functions, may be ideal prototypes for the design of bioinspired polymeric biomaterials, or can provide numerous interaction sites for biomedical polymers. ${ }^{27,28,47,54,60}$ During the past decades, quite a few functional polymeric materials have been developed based on various cell membrane bioinspired strategies, which will be discussed in the following.

\subsection{Directly using cell membranes}

Cell membranes provide stable and functional compartments, preserve the cell architecture, and support signaling and a 
selective transport mediated by the membrane proteins. Cell membranes have been widely applied to various biomedical applications, such as drug/gene delivery (known as cell membranederived vesicles), biosensors, and even biomineralization. ${ }^{18,61-66}$ Whole cell membranes can be used directly to carry drugs or nanoparticles for cell-based drug delivery or other purposes. In the development of cell membrane-derived nanovesicles, the nanovesicles can be derived from various types of cells. For instance, Malhotra et al. derived nanovesicles (NVEs) from red blood cells and loaded them with the hydrophobic drug camptothecin (CPT). Dynamic light scattering (DLS) showed that CPT-NVEs have a hydrodynamic diameter and zeta potential of $189.3 \pm$ $3 \mathrm{~nm}$ and $-8.24 \pm 0.92 \mathrm{mV}$, respectively. Drug release patterns of CPT-NVs indicated 5.5, 30, 50, and $80 \%$ of CPT release within $1,2,6$, and $24 \mathrm{~h}$, respectively. These formulated nanovesicles have a potential to treat lung carcinoma (Fig. 2). ${ }^{67}$ In another work, Dong et al. derived nanovesicles from neutrophils and loaded them with Resolvin D2 (RvD2-HVs) for brain damage recovery during an ischemic stroke. These RvD2-HVs have a hydrodynamic diameter and zeta potential of $\sim 200 \mathrm{~nm}$ and $-14 \mathrm{mV}$, respectively. An in vitro study showed that RvD2-HVs have a much higher ability to bind to the activated endothelial cells than to the non-activated cells. In addition, another in vivo study supported the superior localization of HVs to an injured brain, as shown by a higher fluorescent intensity compared to the control. More importantly, RvD2-HVs treatment in MCAO mice can inhibit the ICAM-1 expression and inflammatory

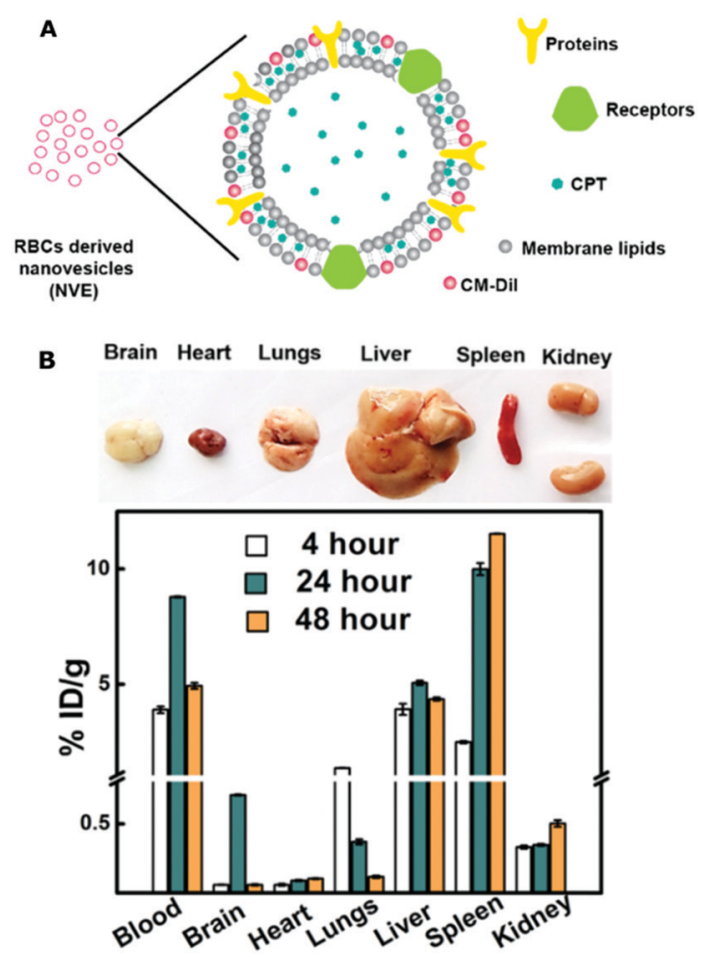

Fig. 2 (A) Structure of RBCs derived nanovesicles; (B) pharmacokinetics and biodistribution of the fluorophore-labeled camptothecin loaded vesicles in mice. Reproduced from ref. 67 with permission from American Chemical Society, Copyright 2019. cytokines, including tumor necrosis factor alpha (TNF- $\alpha$ ), interlukin-6 (IL-6), and interlukin-1 beta (IL-1 $\beta$ ). ${ }^{68}$

As mentioned before, whole cells also have a potential to be used as drug carriers. For instance, Xue et al. developed neutrophil (NE)-based delivery vehicles to diminish glioma in the brain after tumor surgery. ${ }^{69}$ They designed sub $100 \mathrm{~nm}$ paclitaxel-loaded cationic liposomes (PTX-CL) loaded into NEs to obtain NE-based delivery vehicles (PTX-CL/NEs). The inflammatory factors, such as interleukin-8 (IL-8) and tumor necrosis factor $\alpha$ (TNF- $\alpha$ ), which present after tumor removal, activate NEs for migration to the inflamed brain. ${ }^{70}$ An in vitro study showed that PTX-CL was biocompatible for NEs with a loading capacity of $18 \mu \mathrm{g}$ PTX per $10^{6}$ cells. PTX-CL/NEs showed a high penetration ability (nearly $80 \%$ ) in a three-dimensional (3D) multicellular tumor spheroid model. Further study in vivo revealed that this cell-based drug delivery can prolong the survival rate by approximately a month longer than commercial Taxol treatment. There were no significant changes in the bodyweight of the treated mice or other side effects.

In the development of a biosensor, cell membranes are engineered with biochemical sensors for various purposes, such as pathogen detection and tissue engineering. ${ }^{71,72}$ Recently, Qiu et al. developed cell membrane-based biosensors using diacyllipid-DNA conjugates that can self-assemble on the cell membrane based on a hydrophobic interaction between the lipophilic tail and the cellular phospholipid layer. Engineered DNAzymes can cleave their substrates into two fragments and separate the quencher from the fluorescent probe, which subsequently released the fluorescence signals. An additional in vitro study showed that approximately $85 \%$ of the DNAzymes remained on the cell membrane for $2 \mathrm{~h}$, suggesting its stability. The PEG linker helps to reduce the nonspecific interaction between the cell membrane and the oligonucleotide, which maintains its shape. ${ }^{73}$

With the development of numerous cell membrane related technologies, the direct use of whole cell membranes may be applied in an increasing number of biomedical applications. For example, Kim et al. reported a bioorthogonal copper-free click chemistry for in vivo tumor targeted delivery. They introduced targetable glycans (unnatural sialic acids with azide groups) onto the tumor cells through metabolic glycoengineering. Then, the nanoparticles decorated with dibenzyl cyclooctyne were able to chemically bind to the tumor cells with these unnatural sialic acids through in vivo bioorthogonal click chemistry. ${ }^{74}$ Another similar example was also reported by Cheng's group. After introducing an oxyamine group (as the artificial target moiety) onto breast cancer cells, and preparing polymeric nanoparticles with aldehyde groups as the targeting ligands, they obtained an improved cancer targeting performance using the bioorthogonal oxime ligation. ${ }^{75}$ Some other studies not directly related to mammalian cell membranes are also extremely interesting. For example, the biomimetic cell wall prepared using a DNA-templated molecular assembly and crosslinking of polypeptides and polysaccharides, which was bioinspired from plant and microbial cell walls, can act as a shield to encapsulate and protect live mammalian cells from both physical and biological 


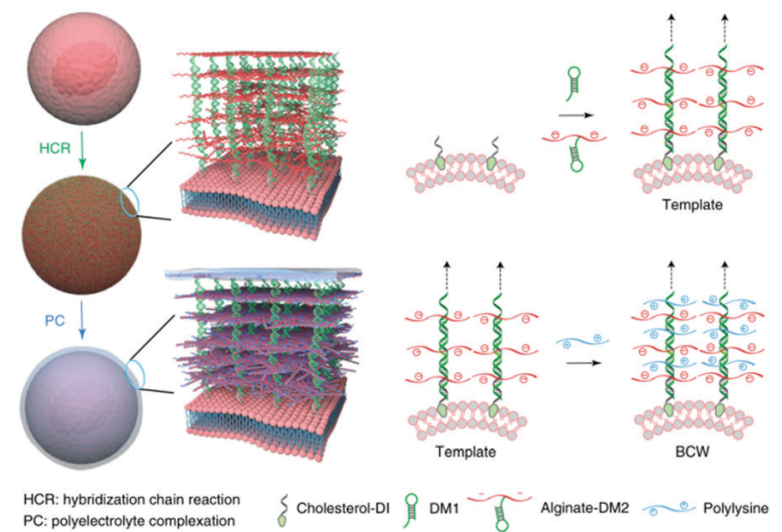

Fig. 3 Schematic illustration of the preparation process of biomimetic cell wall for the protection of mammalian cells. Reproduced from ref. 76 with permission from Springer Nature, Copyright 2019.

assault (Fig. 3). ${ }^{76}$ This effective protection strategy may broaden the biomedical applications of cell membranes.

\subsection{Membrane lipids}

It is known that eukaryotic cells utilize approximately $5 \%$ of their genes to produce thousands of different lipids and fulfil three main functions: $:^{45,77}$ (1) store energy, i.e., as anhydrous reservoirs of caloric reserves, fatty acid, and sterol components for membrane biogenesis; (2) form a matrix of cellular membranes by polar lipids (with both hydrophobic and hydrophilic portions); (3) act as messengers during the processes of molecular recognition and signal transduction. Amphipathic lipids, e.g., phospholipids, glycolipids, and cholesterols construct the important structure of cell membranes through a self-assembly process. ${ }^{27,45,48}$ In addition to their barrier function (separating the intracellular cytoplasm from the outside), membrane lipids are also essential in the stages of germination, tubulation, fission and fusion, which are important for cell division and reproduction. The hydrophobic moieties of phospholipids are integrated and buried into planar lipid bilayers (entropically driven by water), whereas the hydrophilic moieties are oriented toward an aqueous environment. As a major phospholipid in cell membrane, the zwitterionic phosphatidylcholine has been well known for its excellent non-thrombogenic and non-fouling properties, which provides a good prototype for the design of biomaterials with similar functions. ${ }^{78-80}$ A typical example is mimicking the structure of phosphatidylcholine in the cell membrane and facilitating the preparation of polymers or copolymers, of which the 2-methacryloyloxyethyl phosphorylcholine (MPC) has been extensively studied. ${ }^{78,80-90}$

The structure of MPC polymers is electrically neutral and with high hydrophilicity, which is due to their zwitterionic properties. It has been reported that MPC polymers have an extremely low friction in an aqueous environment, and their conformation is quite stable in a high salt solution in a wide range of $\mathrm{pH}$ values. A thick hydration shell with numerous highly mobile free water is formed around the zwitterionic phosphorylcholine groups. ${ }^{91}$ MPC and MPC-based polymers have been widely reported owing to their non-thrombogenic and non-fouling performance. For example, MPC polymers have been grafted onto various material surfaces, e.g., cellulose membranes and hollow fiber membranes, achieving a nonthrombogenic property and without any side effect on their functions, to fabricate various blood-contact biomedical devices such as dialysis membranes and implantable biosensors. ${ }^{72,78,80,82,92-97}$ They also have excellent resistance to the adsorption of various proteins and cells, and are capable of forming a general antifouling interface. ${ }^{26,87,98} \mathrm{In}$ addition, tissue immunoreactions do not occur on an MPC polymer modified surface, e.g., an extremely low angiogenesis and thin encapsulation around the subcutaneously implanted MPC-coated substrates after 28 days. ${ }^{48,81,88,99-101}$ Thus, the modification of various biomaterials with the MPC polymers or direct fabrication MPC-based functional polymers provide a bioinert platform that has similar properties as cell membranes. For example, Kawaguchi et al. grafted the MPC polymer onto a polyethylene surface to prevent the periprosthetic osteolysis of artificial joints. They found that the friction and amount of wear can be significantly decreased in a hip-joint simulator mechanical study through a $3 \times 10^{6}$ cycles of gravimetric loading (equivalent to 3-10 years of physical walking). The PE-MPC surface was also proved to be biologically inert by investigating the macrophages phagocytosis and further bone resorptive response. ${ }^{81}$ Moreover, further modification or copolymerization of PC or MPC-decorated polymeric biomaterials with other moieties such as specific peptides/proteins or polysaccharides can endow them with more interesting functions for biomedical applications. ${ }^{26,102,103}$ For instance, Zhu et al. prepared a cell membrane mimicking conducting copolymer with both a PC grafted block (anti-nonspecific adsorption of proteins and cells) and a peptide ligand grafted block (to mimic the specific interaction between the integrin and extracellular matrix). This copolymer can obviously promote neural cell growth (along with protein secretion) and neurite outgrowth on the electrical stimulation. ${ }^{104}$

There is also another notable cell membrane bioinspired zwitterionic moiety. Brooks et al. first reported an interesting 'PC-reverse' choline phosphate (CP) structure. ${ }^{49}$ The CP group is bioinspired from the PC structure, which is the headgroup of phospholipids widely existing in eukaryotic cell membranes. $\mathrm{CP}$ is also electrically neutral, similar to several other zwitterionic groups such as sulfobetaine, PC, and caboxybetaine. It was proved that the specific CP-PC interaction is through electrostatic interactions, i.e., they form a heterodimer by the two quaternary nitrogen-phosphorous pairs to bind with each other. CP was decorated on hyperbranched polyglycerols through a click chemistry to obtain a functional polymer (HPG-CP) with a high density of the CP groups. The interaction between HPG-CP and the PC on the cell membrane was further confirmed by excluding the effects of membrane proteins and glycoproteins using a PC-based liposome model. HPG-CP can effectively bind and cause the aggregation of human red blood cells (RBCs), and the apparent association constant was 50 times higher than the PC control sample. It was also noted that this cell surface binding or cell aggregation function was 
more effective for a CP-based polymer with multiple CPs ${ }^{49,105}$ because a single hydrated CP-PC interaction is not strong enough. Overall, bioinspired CP-based polymers with a cell membrane adhesive capability can achieve wide biomedical applications, such as drug delivery and tissue engineering, which are separately discussed in detail in the following sections.

\subsection{Glycocalyx}

As the outer layer of the cell membrane, glycocalyx is dominated by glycosylated molecules such as glycoproteins, glycolipids, and other glyco-conjugates, along with the exposure of carbohydrate groups. Glycocalyx mainly directs the specific intercellular interaction such as the cell-cell recognition, and plays an important role in many molecular recognition processes such as cancer cell metastasis, pathogen invasion, bacterial infection, innate immunity, and specific enzymes recognition. Meanwhile, it can also prevent an undesirable non-specific adhesion of biomolecules and cells through a steric repulsion and high hydrophilicity. Thus, the preparation of a biomimetic glycocalyxlike surface can provide a general strategy to obtain biomedical materials with good hydrophilicity, biocompatibility, and specific biomolecule recognition. ${ }^{46,106-121}$ In general, the preparation routes of a glycocalyx-like surface, i.e., glycosylation methods, can be divided into physical methods (e.g., physical adsorption and dipcoating), chemical methods (e.g., surface modification by glycopolymers, surface initiated polymerization of glycomonomers, and synthesis glycopolymers to prepare the substrates), and biochemical methods (e.g., enzymatic transglycosylation). ${ }^{54,122-127}$ For example, Bojarova et al. reviewed the preparation routes and biomedical applications of glycomaterials (e.g., glyconanoparticles and glycodendrimers) based on the specific lectincarbohydrate interactions. ${ }^{17}$ It should be noted that, in the present review, the physical self-assembly or dip-coating of natural polysaccharides (e.g., chitosan and dextransulfate, or polyelectrolytes with different charges) with other polymeric substrates is not emphasized. ${ }^{128,129}$

Holland et al. first reported a glycocalyx-like surface on graphite using oligosaccharide surfactant polymers. ${ }^{46}$ The polymer structure has a flexible poly(vinyl amine) with dextran and alkanoyl side chains, which can provide a dense and confluent oligosaccharide layer similar to that of natural glycocalyx. Finally, the surface can suppress the non-specific adsorption of plasma proteins at more than $90 \%$. Thus, this glycocalyx-like surface with a high surface density of oligosaccharides has potential for preventing the thrombosis on implantable medical devices caused by the non-specific adsorption of plasma proteins. Some further studies have also revealed that a higher grafting density of a glycocalyx-like polymer on a surface may result in a better resistance to non-specific protein adsorption. ${ }^{106}$ Huang et al. also prepared a series of polypeptide block copolymers through the sequential ring-opening polymerization of benzylL-glutamate and propargylglycine. They then decorated the block copolymer using subsequent glycosylation through a click reaction with azide-functionalized galactose. These amphiphilic glycopolypeptides can self-assemble into biologically active micelles

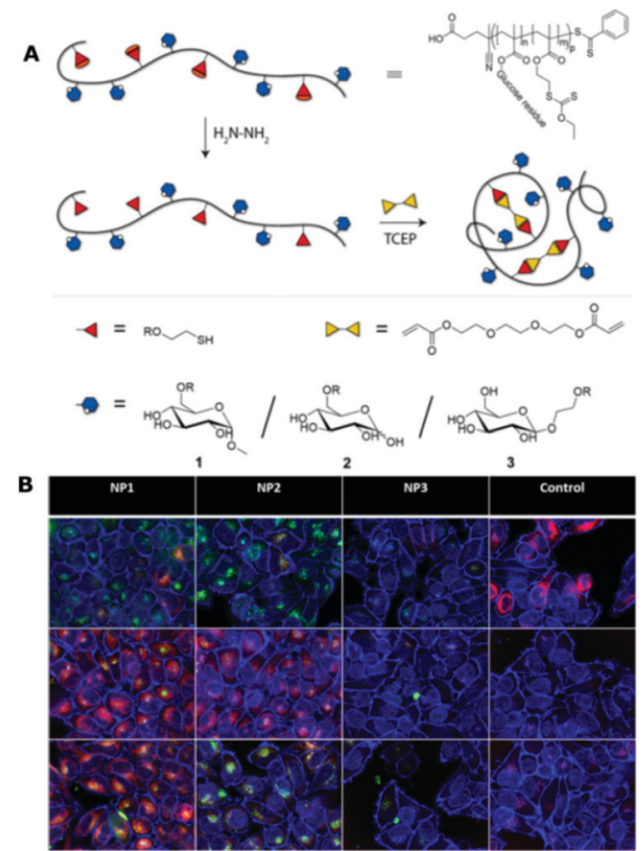

Fig. 4 (A) Schematic illustration of the preparation of Glyco-SCNPs with different glucose moieties; (B) confocal images of HeLa cells incubated with different Glyco-SCNPs for $4 \mathrm{~h}$ (green for Glyco-SCNPs, blue for nuclei and membrane, red for cell compartment). Reproduced from ref. 130 with permission from American Chemical Society, Copyright 2019.

(spherical or worm-like) or polymersomes under different conditions. The bioactive galactose moieties can be displayed on the shell and specifically bind to lectin in a rapid fashion. These glycosylated materials have exhibited a significant potential for targeted drug delivery systems. ${ }^{108}$

The specific cellular targeting property of glycopolymers to various cells has been widely studied. For example, Paulusse et al. prepared a series of single-chain glycopolymer nanoparticles (glyco-SCNPs) through the intramolecular crosslinking of a single polymer chain with linear and cyclic glucose units (Fig. 4). In quantitative binding testes using Concanavalin A (ConA, a type of lectin with four binding sites and specifically sensitive to glucose), the authors revealed a positional dependency of glucose functionalization on the molecular recognition, i.e., the strongest binding while at the $\mathrm{C} 6$ position of glucose remained accessible. The cellular uptake in HeLa cells, which predominantly expresses glucose transporters GLUT1 and GLUT3, also exhibits their potential for ligand-based target drug delivery and imaging. ${ }^{130}$ A very recent work also reported a series of pentavalent biotinylated poly(ethyleneimine) (PEI) glycopolymers (Fig. 5). ${ }^{131}$ This interesting biohybrid structure can remain stable for weeks after the polyassociation process. The tumor cell targeting capability of the biohybrid structure is also controllable as indicated through cellular uptake studies using several cell lines (e.g., HEK293T, HT-29, and SBC-2).

\subsection{Membrane proteins}

Cell membrane proteins include integral membrane proteins and peripheral membranes proteins. ${ }^{28,47,132}$ Their main function 


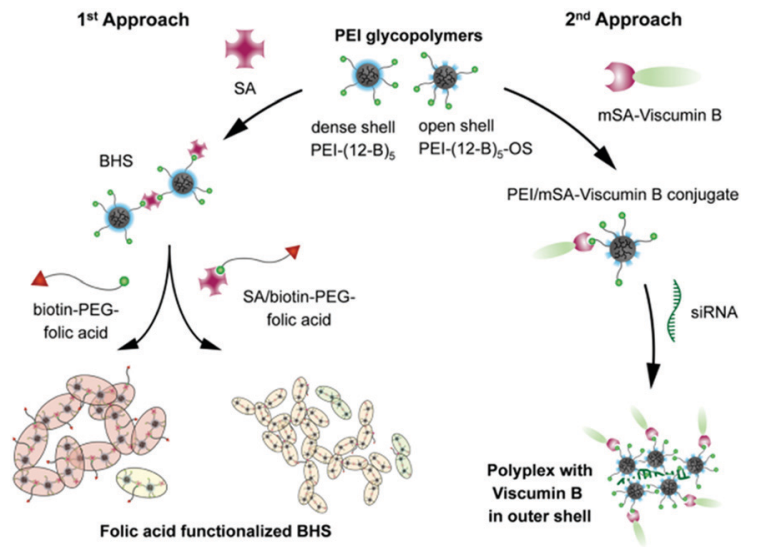

Fig. 5 The illustration of the formation of biohybrid structures (BHS). The pentavalent biotinylated PEI glycopolymers, tetrameric streptavidin (SA), folic acid, monovalent-streptavidin fused protein viscumin B (mSAviscumin B), small interfering RNA (siRNA) are used in different approaches. Reproduced from ref. 131 with permission from American Chemical Society, Copyright 2019.

is to form various biological transport channels (e.g., numerous aquaporins and ion channel proteins). ${ }^{58,133,134}$ Many cell membrane protein bioinspired polymeric materials have been developed for biomedical applications, mainly based on two types of strategies: (1) the reconstitution of natural cell membrane proteins or biopores (e.g., pore-forming peptides) in polymeric materials to form a hybrid membrane through insertion, encapsulation, and attachment, etc. $;^{47,133-135}$ (2) fabrication of smart polymers to mimic specific functions of cell membrane proteins. ${ }^{52,136,137}$ Through these methods, quite a few membrane proteins or their biomimetic analogues have been utilized to develop various functional biomedical materials. It should be noted that such biomedical applications based on targeting of the cell membrane proteins (e.g., targeting the folate receptor on cancer cells $\left.{ }^{102,138}\right)$ are not specifically discussed in this review.

For example, the cell membrane protein aquaporin (AqpZ) is a highly selective water channel, which can transport $\sim 4$ billion water molecules per second per aquaporin, but reject other molecules such as salts at the same time. After being inserted into synthetic membranes, AqpZ helps obtain a much higher water permeability than commercial available products. ${ }^{139}$ Aleman et al. also reported a poly( $N$-methyl-pyrrole) membrane immobilized with a $\beta$-barrel membrane protein (Omp2a) to form ion channels. Its passive ion transport was tested in the presence of $\mathrm{Na}^{+}$and $\mathrm{K}^{+}$with similar concentrations to that in blood. In addition to the good biocompatibility and biodegradability, this film exhibited clear resistance changes in response to the changes in ion concentration, exhibiting great potential for biosensors and bioinspired channels. ${ }^{133}$

The outer membrane protein $\mathrm{F}$ (OmpF porin) is a wellknown ionic channel with high selectivity, gating, and rectification properties. ${ }^{140}$ To mimic its functions, an asymmetric block copolymer membrane, i.e., polystyrene- $b$-poly(4-vinylpyridine), was combined with a porous anodic alumina membrane to form a multifunctional heterogeneous membrane (Fig. 6). The OmpE

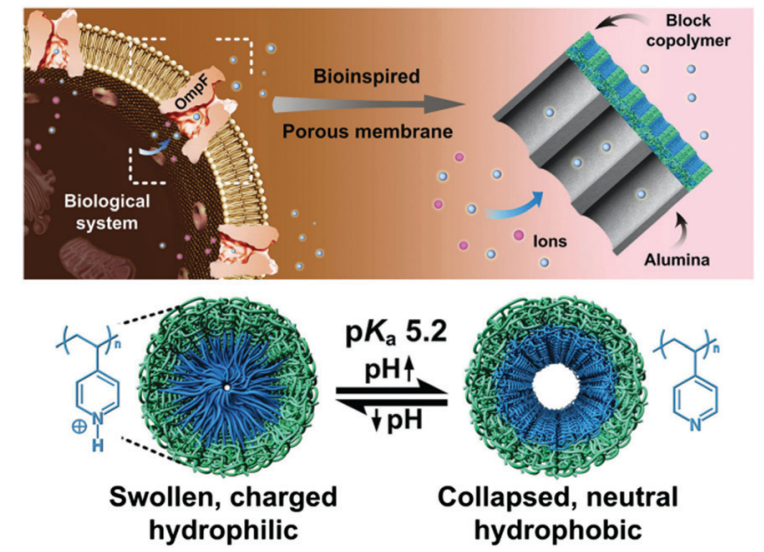

Fig. 6 Schematic illustration of the heterogeneous membrane bioinspired from the cell membrane protein OmpF porin, exhibiting ultrahigh ionic rectification and selective ionic gating in response to $\mathrm{pH}$ changes. Reproduced from ref. 52 with permission from John Wiley and Sons, Copyright 2015.

porin bioinspired membrane exhibited a ultrahigh ionic rectification ratio ( $\sim 489)$. In addition, it has a high efficiency for selective ionic gating, i.e., anion- or cation-selective gating, by tuning the $\mathrm{pH}$-sensitive groups, similar to that of the natural OmpE porin. ${ }^{52}$ Using a similar strategy, this research group recently developed a bioinspired heterogenous ion pump membrane using block copolymers with unidirectional selective ion pumping and $\mathrm{pH}$-responsive gating properties for biosensing. ${ }^{137}$

\section{Biomedical applications of functional polymeric materials bioinspired by cell membrane}

\subsection{Drug/gene delivery}

Significant efforts have been made in the enhancement of the in vivo nanoparticle resident time for target and effective drug delivery through a surface modification to bypass the macrophage uptake and systemic clearance. A large number of drug delivery systems are made from polymers including dendrimers, micelles, nanoparticles and polymer-drug conjugates, as well as liposomes, etc. It is well-known that cancer drug delivery systems require a tight retention of the drug during the circulation, efficient targeting of the tumor, quick penetration into the tumor tissue, quick internalization into the tumor cells, and a fast intracellular release of the drug within the tumor cells. ${ }^{141,142}$ To fulfill these requirements, various interesting and effective drug/gene delivery systems bioinspired from cell membranes have been developed, specifically owing to their anti-fouling, disease targeting properties, and excellent biocompatibility.

A top-down approach to camouflage natural circulating cells has recently received significant attention in the biomedical field. By coating nanoparticles with natural cell membranes derived from various types of cells (e.g., red blood cells, platelets, macrophages, and cancer cells), a long circulation of the cargo delivery and self-recognition by the host cells can be achieved. ${ }^{143}$ 
The cell membranes can be isolated through ultracentrifugation and coated on nanoparticles using extrusion, sonication, or electroporation methods. ${ }^{144,145}$ This allows the membrane proteins from the source cells to be transferred onto the surface of the enveloped nanoparticles. Among them, red blood cells are the gold standard for cell membrane coating and are possible for further functionalization using different types of techniques such as lipid insertion, biotin-avidin, EDC/NHS coupling, antibody/ligand-receptor conjugation, and passive adsorption (hitchhiking) for theranostic purposes. ${ }^{146}$

The RBC membrane coating technique was pioneered by Zhang's group in 2011. They used an extrusion technique to fuse poly(lactic-co-glycolic acid) (PLGA) nanoparticles and RBC membrane vesicles based on electrostatic interactions between cell membranes and negative-charged PLGA nanoparticles (RBCNPs) (Fig. 7). ${ }^{147}$ They also demonstrated the successful coating of a platelet membrane on PLGA nanoparticles (platelet membrane-cloaked nanoparticles (PNPs)). An in vitro study of the NP adhesion properties to type IV collagen showed that the PNPs have enhanced collagen-specific targeting abilities compared with bare NPs and RBCNPs, indicating a similar feature with platelets. Interestingly, a Western blot analysis confirmed that the platelet membrane immunomodulatory proteins (CD47, CD55, and CD59), the platelet integrin ( $\alpha \mathrm{IIb}, \alpha 2, \alpha 5, \alpha 6, \beta 1$, and $\beta 3$ ), and other transmembrane proteins (GPIb $\alpha$, GPIV, GPV, GPVI, GPIX, and CLEC-2) can be successfully transferred onto PNPs. An in vivo study of the therapeutic potential of PNPs on coronary restenosis-model rats revealed that docetaxel-loaded PNPs (PNP-Dtxl) show a selective adherence to the damaged vasculatures and effectively inhibit neointima growth in balloondenuded rats after 2 weeks of treatment. ${ }^{148}$

It was further demonstrated that a right-side-out assembly of the cell membrane coating can only be achieved by a repulsion

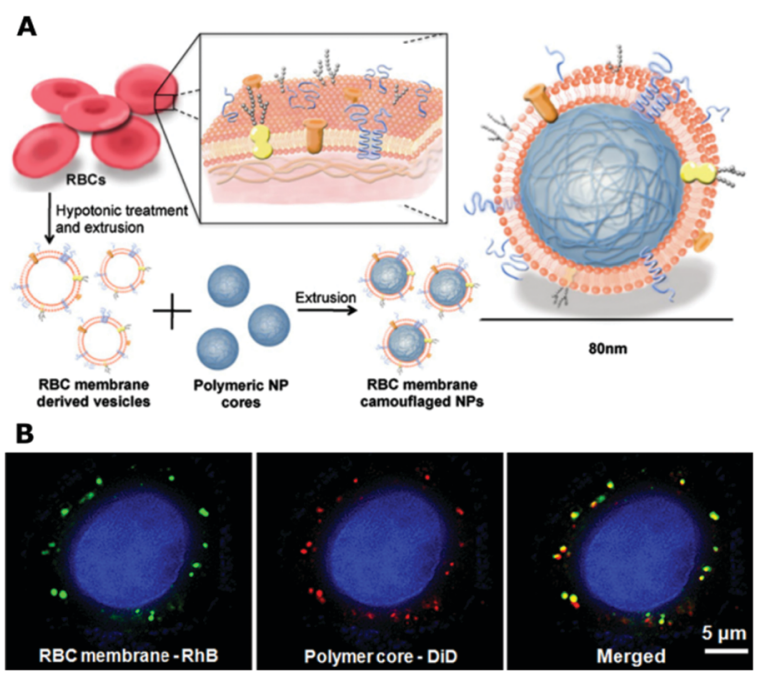

Fig. 7 (A) The preparation route of RBC membrane coated PLGA nanoparticles; (B) fluorescence microscopy images of the RBC membrane (green) and PLGA cores (red) after being internalized by HeLa cells. Reproduced from ref. 147 with permission from National Academy of Sciences, Copyright 2011. between negatively-charged nanoparticle cores and the cell membranes. Meanwhile, the attraction between positivelycharged cores and the cell membranes induced an aggregation. ${ }^{149}$ In addition, Xie et al. proposed a "molecular affinity" strategy using an intracellular domain of band 3 transmembrane receptors as "grippers" during the coating process. By using a peptide ligand attached to the surface of nanoparticles, the specific interaction between P4.2-derived peptide ligands and band 3 receptors form a "hidden peptide button" that establishes the correct orientation. ${ }^{150}$

Interestingly, polymeric-core nanoparticles with different sizes ranging from 65 to $340 \mathrm{~nm}$ have been successfully wrapped using RBC membranes. ${ }^{149}$ However, the size of RBCm-cloaked nanoparticles greatly influences their circulation and biodistribution in the liver. The larger the particle size is, the more they tend to be entrapped in the liver and the shorter their half-life. ${ }^{151}$ Over the last decade, biomimetic nanoparticles using cell membrane coating have shown considerable outcomes in treating various types of diseases, such as cancer and cardiovascular diseases.

In cancer drug delivery, several designs of RBCm-cloaked nanoparticles have shown excellent targeting, imaging, and theranostic abilities. ${ }^{146,152}$ For instance, Guo et al. developed RBCm-enveloped PLGA nanoparticles encapsulating antigenic peptide (hgp100 $25-33$ ) and monophosphoryl lipid A to function as immune cell activation with redox-sensitive linkers. To enhance its targeting ability, the RBCm shell was functionalized with mannose through a lipid insertion. These complex nanovaccines have the capability to target dendritic cells in the lymphatic organ, and the redox-sensitive property can enhance the release of antigens in the tumor area. An in vivo study showed a successful tumor growth inhibition of $76.6 \%$ and a suppression of tumor metastasis in prophylactic, therapeutic, and metastatic melanoma models. ${ }^{153}$

The research group of Feng and Zhang reported a series of highly effective tumor therapy systems coated by cracked cancer cell membranes (CCCM). ${ }^{154-157}$ The rationality is that the tumor cell membrane surface has numerous specific proteins such as focal adhesion proteins/kinase and integrin to make them aggregate and form solid tumors, ${ }^{158-162}$ and thus the CCCM-coated nanoparticles prefer to recognize homotypic cancer cells. ${ }^{154}$ This strategy was applied in the preparation of highly tumor-selective targeting drug/gene delivery systems (for homologous tumors rather than heterologous tumors), along with other functions such as MR imaging. Most recently, they combined immunotherapy and traditional oncotherapy by fusing the cytomembranes of both cancer and dendritic cells (Fig. 8). ${ }^{157}$ The fused cell cytomembrane exhibited an efficient expression of the cancer antigens in the form of an antigen peptide-major histocompatibility complex (pMHC), which was discerned, processed and presented by dendritic cells. It could also express the immunological co-stimulatory molecules. Thus, the fused cell cytomembranes could induce a very strong and durable immune response. Finally, the authors presented a successful combined irradiation-mediated photodynamic therapy and fused cell membrane induced immunotherapy for both primary and distant tumors. Several other groups have also successfully 
A

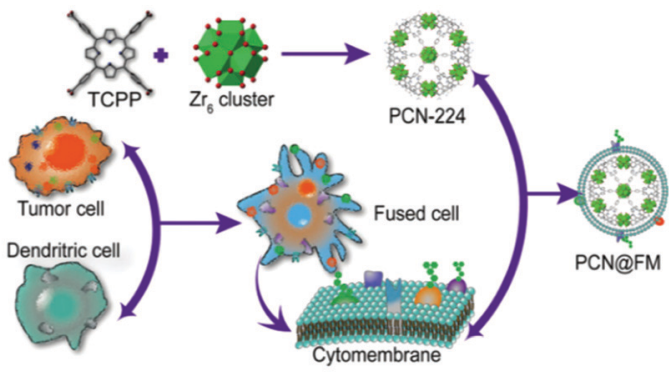

B

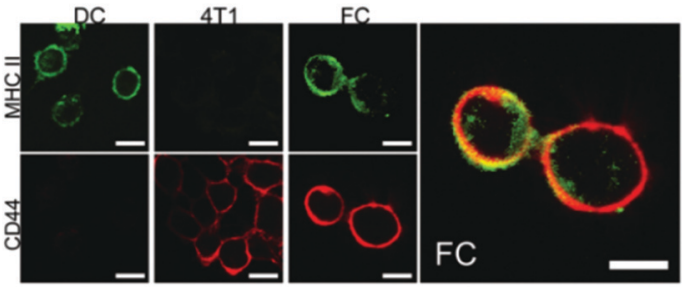

Fig. 8 (A) Schematic illustration of the preparation process of drug delivery nanoparticles coated by the cytomembrane of fused cancer cells and dendritic cells for combined tumor therapy. (B) CLSM images of the stained cancer cells (4T1), dendritic cells (DC), and fused cells (FC). Reproduced from ref. 157 with permission from John Wiley and Sons, Copyright 2019.

applied this cancer cell membrane coating strategy to develop various tumor-homing drug delivery systems for precise cancer targeting therapy. ${ }^{163}$

Biomimetic nanotherapy can also be used to treat cardiovascular-related diseases. Wang et al., for instance, designed RBCm-cloaked PLGA nanoparticles encapsulating rapamycin drugs (RBC/RAP@PLGA) to treat atherosclerosis (Fig. 9). ${ }^{53}$ The RBC/RAP@PLGA was delivered to the atherosclerosis plaques through the EPR effect-mediated passive targeting. The dynamic light scattering (DLS) showed that the uncoated NPs had a hydrodynamic size of $81.5 \pm 4.5 \mathrm{~nm}$, whereas the coated NPs indicated a larger size $(97.4 \pm 2.4 \mathrm{~nm})$, as proved by TEM. In addition, the zeta potential of the coated NPs showed a lower value than the uncoated NPs $(-28.7 \pm 1.7 \mathrm{mV}$ versus $-21.4 \pm 0.6 \mathrm{mV})$, which indicated that the coated NPs had a similar surface charge as the RBC membrane vesicles $(-31.0 \pm 2.7 \mathrm{mV})$. A Western blot analysis showed that the CD47 glycoproteins, which are responsible for inhibiting macrophage phagocytosis, were successfully transferred to RAP@PLGA. Ex vivo fluorescent imaging demonstrated the superior targeting ability of $\mathrm{RBC} /$ RAP@PLGA to the atherosclerotic plaques. After treatment for 1 month, the biomimetic nanotherapy significantly reduced the lesion area to $6.24 \%$ compared to the control $(20.13 \%)$ and the plaque area by $\sim 17 \%$, as quantified from Oil Red O (ORO) staining of the aorta. More importantly, RBC/RAP@PLGA showed in vivo biocompatibility with no significant toxicity to the main organs and body weight changes, which suggest its potential for clinical trials. In the near future, combining a biomimetic design with stimuli-responsive nanoparticles will amplify its efficacy to treat various types of diseases. ${ }^{164}$

As a phospholipid polymer, 2-methacryloyloxyethyl phosphorylcholine (MPC) based polymers have been widely used in gene/drug delivery systems due to their excellent biocompatibility,

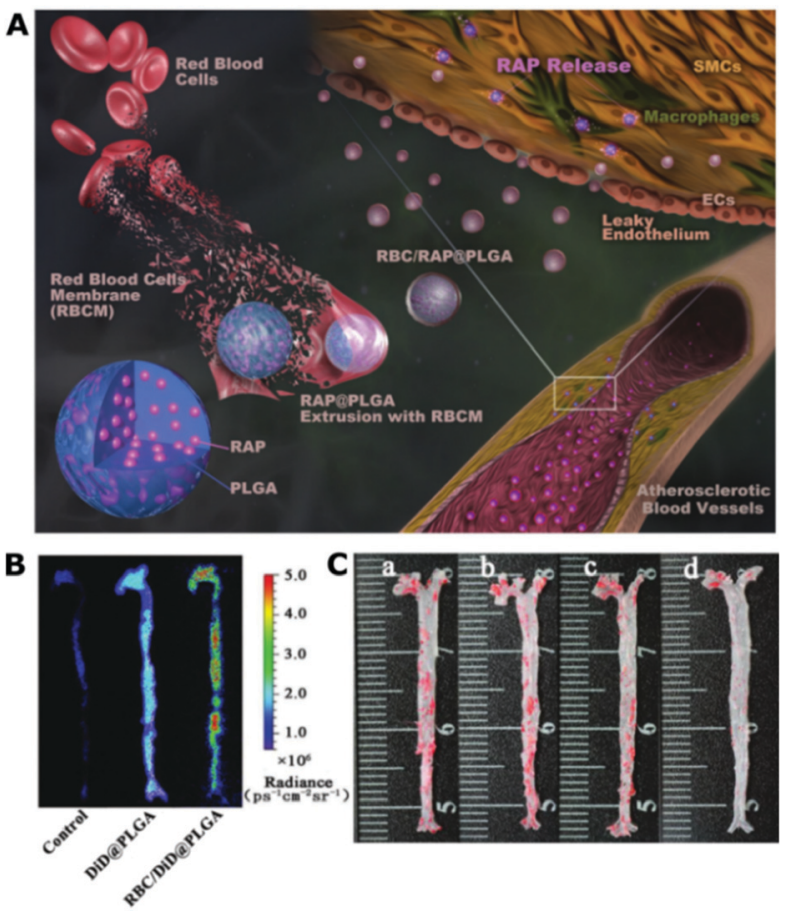

Fig. 9 (A) Illustrations displaying the preparation of RBC/RAP@PLGA for the treatment of atherosclerosis. (B) The ex vivo fluorescence images of the aorta of $\mathrm{ApoE}^{-1-}$ mice after injection of $5 \%$ sucrose (control), DiD@PLGA, and RBC/DiD@PLGA. (C) The en face ORO stained images of aortas from each group ( $a$, control; b, free drug; c, RAP@PLGA; d, RBC/RAP@PLGA). Reproduced from ref. 53 with permission from the Authors (open access), Wiley-VCH, Copyright 2019.

and even called an 'artificial cell membrane'. ${ }^{26,165-168}$ It was reported that the MPC polymer coated liposomes can increase the transfection efficiency of plasmid DNA by up to two orders of magnitude owing to the enhanced cellular uptake and postnuclear delivery. The coating of MPC polymer reduced the $\zeta$-potential of the liposome, helping the display of functional negatively charged peptide (GALA, for endosomal escape) on the cationic liposome by providing shielding effect from electrostatic interactions. ${ }^{169} \mathrm{~A}$ series of diblock copolymers with cationic segment (primary amine) and MPC segment were also synthesized for gene delivery, in which the MPC polymers served as a stealth layer, exhibiting low protein adsorption, minimum toxicity and high gene transfection efficiency. ${ }^{170}$ In addition, MPC-based polymers can be more effective in gene delivery when designing the composition, size, and chain topologies of a non-viral gene vector in an optimum way. ${ }^{167}$

Drug carriers based on the MPC polymer can also be combined with various stimuli sensitivities. For example, Emrick et al. designed disulfide cross-linked micelles containing an MCP block, which can be stable in a solution for weeks. ${ }^{171}$ In this system, camptothecin (CPT) was conjugated to the hydrophobic block of the copolymer through a disulfide linkage as a prodrug micelle. While being treated with dithiothreitol (DTT) as the reducing agent, the micelle can release CPT in a triggered manner. Shen et al. also reported an enzyme-responsive dendrimer for anti-cancer drug delivery. ${ }^{172}$ The dendrimer 
was intentionally modified with MPC units to achieve a long blood circulation time by reducing the nonspecific binding of the plasma proteins. When exposed to phospholipase $\mathrm{C}$, which is overexpressed in cancer cells, the dendrimer can be degraded to release the encapsulated Doxorubicin (DOX). Thus, the enzyme-responsive DOX delivery system is safe for normal cells while highly toxic to cancer cells. Recently, an MPC block was also designed as a zwitterionic shell for a polymeric prodrug of DOX, which uses folate as the cancer cell targeting moiety and a Schiff base bond (benzoic-imine, formed by the aldehyde group of the polymer and the amino group of the DOX) as the pH-responsive moiety. ${ }^{102}$ The DOX accumulative release from this prodrug is up to $70 \%$ at pH 5.0 after the cleavage of the benzoic-imine bond. Another research group also synthesized a series of $\mathrm{pH} /$ redox dual-responsive amphiphilic polymers containing zwitterionic PMPC (as a hydrophilic block), poly( $\varepsilon$-caprolactone) (PCL, as a hydrophobic block), $\operatorname{poly}(N, N$ diethylaminoethyl methacrylate) (PDEA, as a pH-responsive block), and disulfide bonds as the redox-responsive unit. The location of the PDEA and disulfide bond in this copolymer was varied to investigate the effect on the encapsulation, blood circulation, and tumor site accumulation/release of DOX as an anti-cancer drug. ${ }^{173}$

Some other interesting functions have also been collaborated with MPC polymer to obtain multifunctional drug delivery systems. For instance, tetraphenylethene is a typical molecule with an aggregation induced emission (AIE) phenomenon. It is conjugated to an MPC-based pH-responsive zwitterionic copolymer, i.e., poly(2-methacryloyloxyethyl phosphorylcholine-co-2-(4-formylphenoxy)ethyl methacrylate), via the acid-cleavable hydrazone bond. ${ }^{174}$ The micelles formed have a good physiological stability with low nonspecific protein adsorption, which is contributed by the zwitterionic property of the MPC block. After being loaded with DOX, the micelles have simultaneous AIE imaging and pH-responsive chemotherapy capabilities for cancer theranostics. In an acidic environment ( $\mathrm{pH} 5.0)$ of the tumor tissues, the micelles exhibit an obvious swelling after cleavage of the hydrophobic TPE moiety, leading to a $\mathrm{pH}$-triggered DOX release profile and high-quality AIE imaging. Another interesting anti-cancer drug delivery system was also reported by combining chemotherapy and photodynamic therapy based on an MPC-containing hydrogel-like polyprodrug. ${ }^{175}$ The authors synthesized MPC with a platinum(Iv) complex-based monomer, which can generate a highly toxic Pt(II) in situ to act as a chemotherapeutic species. Meanwhile, the system can also produce the reactive oxygen species (ROS) at a high level while being exposed to light for only $5 \mathrm{~min}$, without any photosensitizer or the presence/consumption of endogenous oxygen. The prolonged circulation time, sustained drug release profile, and even reversing drug resistance property of the system make it a potential candidate for anti-tumor therapy.

Variable diseases can be treated using MPC-based polymeric drug delivery systems, not only cancer therapy. For instance, although local drug treatment is effective for the healing of bone fracture, it still requires systemic administration in some complex clinic fractures such as an osteoporotic vertebral compression fracture owing to an access restriction. Recently, Yang et al. reported an MPC-based nanocapsule for the systemic administration of the bone growth factor (BMP-2), ${ }^{98}$ to overcome its usual shortcomings such as the in vivo instability, insufficient distribution at the bone fracture site, and the side effects of overused growth factors. This interesting strategy was based on two key points. First, the MPC polymeric shell can effectively stabilize BMP-2, prolonging its circulation time by reducing the nonspecific protein adsorption, and facilitate the drug accumulation at the bone fracture sites through leaky blood vessels. Second, the introduced bisacryloylated VPLGVRTK peptide is enzymeresponsive, i.e., it can be cleaved by over-expressed matrix metalloproteinases at the bone fracture sites. In this way, the bioactivity of BMP-2 is well maintained, and the circulation time is prolonged with a half-life of approximately $48 \mathrm{~h}$, and thus the nanocapsule can be passively delivered to the bone fracture site after systemic administration. Next, the polymeric shell was degraded through the enzyme-responsive mechanism to release the growth factor, leading to an effective bone repair, e.g., the bone volume / total volume of data was around double that of the control group (60.13\% versus $32.09 \%)$.

CP-Based polymers bioinspired from cell membrane lipids have also been investigated for drug delivery. It should be noted that drug delivery strategies based on 'PC-reversed ' CP polymers are quite different from those based on PC-based polymers. $\mathrm{Yu}$ et al. first designed a thermosensitive random copolymer using oligo(ethylene oxide)methacrylate and 2-(2-methoxyethoxy)ethyl methacrylate ( $p$ (OEOMA-co-MEMA)), and then introduced CP groups to the backbone. ${ }^{176}$ The polymer has a tunable lower critical solution temperature (LCST), and the adhesion of the polymer on the cell membrane can be reversed, because the accessibility of CP groups to the cell membrane is decreased after the polymer exhibiting hydrophobicity and aggregating together above the LCST. They then developed a pH and thermoresponsive CP-based drug carrier capable of targeting the acidic microenvironment of solid tumors. ${ }^{177}$ The polymer was synthesized from CP-decorated tetraethoxymethacrylate (providing thermosensitivity) and dimethylaminoethyl methacrylate (DMAE, providing $\mathrm{pH}$ sensitivity). Adhesion to the tumor cells was still based on a CP-PC interaction. When the DMAE block was uncharged at $\mathrm{pH}$ 7.4, the copolymer showed a LCST. However, while the DMAE block was charged at the acidic tumor environment ( $\mathrm{pH}$ 6.8), LCST did not occur because of the ionization hydrophilicity. Overall, this polymer exhibits an interesting behavior in that it can bind tightly to tumor cells at $\mathrm{pH} 6.8$ but does not bind to normal cells at $\mathrm{pH}$ 7.4. Recently, CP-based polymeric drug carriers have been further designed with multiple functions such as with a bioreducible disulfide bond, or conjugation to doxorubicin as a prodrug, to obtain an enhanced cellular uptake and rapid internalization for the controlled release of anti-tumor drugs. ${ }^{178-180}$

Quite a few cell membrane bioinspired glycopolymers have also been developed as effective gene delivery systems. ${ }^{181-185}$ For instance, Reineke et al. reported a series of glycopolymers, i.e., poly(glycoamidoamine), as vehicles for the delivery of plasmid DNA. Through a cellular delivery test with pharmacological endocytosis inhibitors, they revealed the cellular 
internalization mechanism of these glycopolymers, which are mainly mediated by caveolae, while also involving clathrincoated vesicles and macropinosomes, i.e., a so-called caveolae/ raft-mediated endocytosis. This pathways is not identical to that of polyethyleneimine (PEI, the gold-standard of non-viral gene vector), indicating a different cellular internalization mechanism of the glycopolymers. ${ }^{181}$ When the poly(glycoamidoamine) was applied to deliver oligodeoxynucleotide decoys to cardiomyoblasts and a mouse heart, it could mediate high levels of DNA nuclear uptake ( $\sim 90 \%)$ and effectively block the activation of the related transcription factor. ${ }^{182}$ Glycopolymers can also be designed into a dendritic structure by functionalizing with hyperbranched PEI, ${ }^{183}$ or complexing with $\mathrm{PEI}^{184}$ to obtain functional gene delivery systems. In particular, the glycopolymers/ PEI can form a serum-tolerant gene vector to hepatocytes with improved efficiency. In this study, the comb-shaped dextran- $g$ poly(2-dimethylaminoethyl methacrylate-co-2-lactobionamidoethyl methacrylate) was synthesized and complexed with PEI and plasmid DNA. The polyplex exhibited better stability and gene transfection efficiency (two orders of magnitude higher than that of PEI alone) in a serum-containing medium, which was mainly due to the serum-tolerant property of the glycopolymer. ${ }^{184}$

Notably, Ji et al. combined the biomimetic strategies of both phospholipids and glycolipids in cell membranes (Fig. 10). They first prepared a chitosan oligosaccharide modified by zwitterionic phosphorylcholine to mimic the hydrophilic head groups on lipids, and then grafted hydrophobic stearic acid to mimic the lipid fatty acids. The copolymer was able to self-assemble into zwitterionic micelles with cell membrane bioinspired properties such as a high stability in a proteincontaining, high salt content medium within a wide $\mathrm{pH}$ range. The anti-cancer drug DOX can be encapsulated and delivered into cancer cells with sustained drug release profiles. ${ }^{186}$ Several research groups have also reported glycocalyx-biomimicking

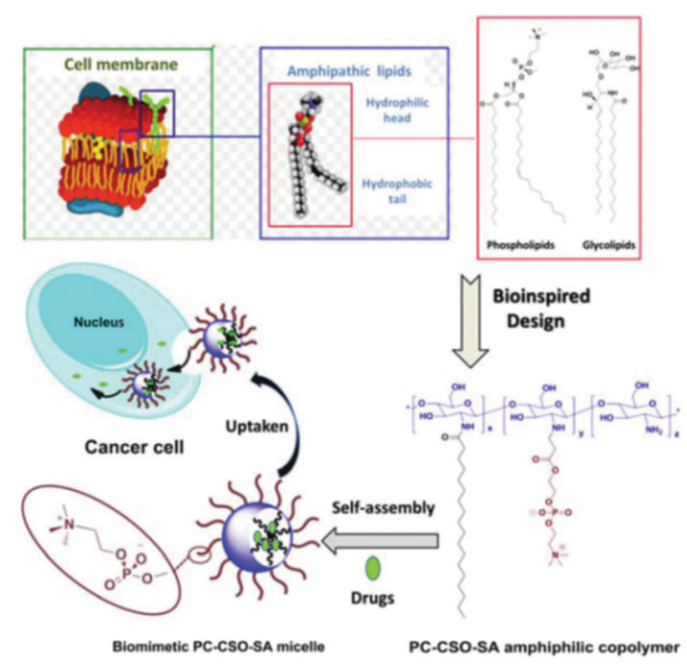

Fig. 10 Schematic illustration of the cell membrane bioinspired polymeric micelles for anti-cancer drug delivery. The glycopolymer is bioinspired from both phospholipids and glycolipids in cell membranes. Reproduced from ref. 186 with permission from The Royal Society of Chemistry, Copyright 2015. nanoparticles, which can be loaded with a platinum anti-cancer drug, ${ }^{187}$ or act on the macrophages/T cells, ${ }^{188,189}$ for a targeted and effective anti-tumor therapy.

Glycocalyx bioinspired glycopolymers also have wide biomedical applications other than in tumor therapy. For instance, a key factor to maintaining the integrity and barrier function of ocular surface epithelial glycocalyx is the galectin-3 multimerization and recognition of lactosyl residues. Thus, two membrane-anchored glycopolymers, i.e., cellobiose- and lactosecontaining glycopolymers were synthesized to effectively modulate the barrier function of ocular surface glycocalyx. They can be therapeutically applied to transiently enhance the efficiency of topical drug delivery. ${ }^{190}$ Most recently, Ratner et al. also reported the synthesis of mannosylated ciprofloxacin polymeric prodrugs, which can be delivered in a targeted fashion and internalized by alveolar macrophages through a mannose receptor (CD206) mediated internalization after pulmonary administration. This targeting antibiotic prodrug was effective for alveolar macrophage infection, i.e., the mice survival was $87.5 \%$ based on a treatment regimen with infection. ${ }^{191}$

\subsection{Implant materials}

Implant materials require antibiofouling surface for decreased inflammation and fibrosis which lead to the failure of implantion, to obtain long-term biocompatibility in vivo. Although poly(2hydroxyethyl methacrylate) (HEMA) and $N$-vinyl-2-pyrrolidinone (NVP) have already been used for fabricating the antibiofouling coating for implant materials, cell membrane bioinspired polymers with excellent antifouling property, i.e., anti-protein and anti-thrombosis adsorption, as well as high hydrophilicity, can provide a general platform to construct functional coatings with excellent blood compatibility and tissue compatibility, through their resistance to proteins and cells. For example, various MPC-based polymeric coatings have been designed for various implant materials such as intravascular stents, corneal substitutes, tympanostomy tube implants, small-diameter vascular grafts, hollow fiber membrane based artificial lungs, artificial joint cartilage, tooth adhesives, implantable drug release devices, and implantable sensors. ${ }^{82,92,96,192-199}$

Intravascular stents have been widely used as implantable medical devices in coronary, carotid, renal, peripheral, and intracranial arteries. Usually, these stents are made of metals such as stainless steel and various alloys. Although drug eluting stents have significantly reduced the restenosis, they can cause a late stent thrombosis, which results from the proinflammatory characteristic of the polymeric coating and the incomplete endothelialization. Thus, the stent surface modification using cell membrane bioinspired polymers provides an effective method to solve this problem. ${ }^{82,195,200,201}$ For example, drug eluting stents have a simultaneous requirement of a sustained inhibition of the proliferation of smooth muscle cells (SMCs) but a promotion of the endothelial cells (ECs). Ji et al. prepared a zwitterionic MPC-based methacrylate coating on the stent surface to load rapamycin and introduced an EC-specific ligand peptide (Arg-Glu-Asp-Val, REDV). Their interesting results showed that the coating can resist the nonspecific adsorption of SMCs while 
enhancing the attachment of ECs after 8 days of drug release. In their work, a rabbit iliac injury experiment was carried out using this coated stainless steel stent, resulting in a significantly enhanced re-endothelialization without neointimal hyperplasia. ${ }^{201}$ Hotta et al. also developed a drug-eluting coating for stents using MPC polymer as the non-thrombogenic unit, and a micropatterned hydrogenated amorphous carbon as the cell-compatible unit. The stent surface can effectively suppress the platelet adhesion and promote the proliferation of endothelial cells. ${ }^{82}$

Most recently, an MPC polymer was grafted onto the surface of $316 \mathrm{~L}$ stainless steel through a photo-induced radical polymerization to endow it osteogenic and antibacterial properties for orthopedic applications. ${ }^{202}$ Ghosh et al. also modified the commonly used a titanium alloy (Ti6Al4V) with an MPC polymer with a uniform surface, less roughness, and low cell attachment to fulfill the requirement of hip arthroplasty. ${ }^{203}$

Implantable glucose sensors are very useful for monitoring the blood glucose level of diabetics; however, they still lack in vivo long-term reliability owing to the inflammation and fibrosis around the sensors, which both decrease their sensitivity (blocking glucose transportation) and shorten their lifetime. To address this problem, Wang et al. developed a hydrogel coating incorporated with $\mathrm{pH}$-sensitive molecularly imprinted polymer (MIP) nanospheres. ${ }^{96}$ The MIP nanospheres (4 wt\%) are loaded with the anti-inflammatory drug, dexamethasone-21 phosphate disodium (DXP). This coating shows a faster release profile of DXP at a lower pH value, which has potential for the successful suppression of the inflammation and an improvement in their lifetime.

A glycocalyx-like polymeric layer can also provide an effective anti-fouling surface for implant biomaterials to suppress protein adsorption, reduce platelets, and bacterial and mammalian cell adhesion. ${ }^{204-206}$ For example, Marchant et al. synthesized dendritic saccharide surfactant polymers using poly(amidoamine) and maltose dendron, which can form a dense protective layer, similar to glycocalyx, to effectively decrease platelet adhesion by more than $90 \% .^{204}$ A similar strategy can also be applied to a silicone elastomer, i.e., polydimethylsiloxane, to achieve nonadhesive glycocalyx-like properties. ${ }^{205}$ Interestingly, after being coated on the surface of commercial totally implantable venous access ports (TIVAPs) in a rat model with a biofilm infection from two biofilm-forming pathogens, the biomimetic glycocalyxlike polymer helped to effectively prevent the initial adhesion of the pathogens. In this way, the coated TIVAPs could result in a 4-log reduction of biofilm formation and the associated occlusion, which exhibited significant potential to minimize the clinic complications caused by implantable medical devices. ${ }^{206}$ Stupp et al. also reported supramolecular sulfated glycopeptide nanostructures with a filamentous shape and an internal $\beta$-sheet backbone. The nanostructures can display trisulfated monosaccharide on the surface to bind specific proteins. They were designed to amplify the signaling of bone morphogenetic protein 2 (BMP-2, important growth factor for bone repair) by utilizing the specific affinity between the polysaccharides and proteins. Finally, they can promote the bone regeneration in the spine at a 100 -fold lower dose than expected. ${ }^{207}$

\subsection{Tissue engineering}

It is well known that tissue engineering is based on three main factors: cells, scaffolds and growth factors. Scaffold materials play very important roles in the development of tissue engineering to repair or replace various tissues such as bone, skin and blood vessels. Different from traditional implant materials, tissue engineering scaffolds require material surface properties for cell adhesion and proliferation, in addition to the non-fouling and biocompatibility properties. However, a dilemma occurs because cell adhesion is mostly guided by cell adhesion-mediating proteins/peptides, ${ }^{208,209}$ and non-fouling material surfaces, e.g., poly(ethylene glycol) modified or traditional zwitterionized surfaces, may thus inhibit cell adhesion after suppressing protein adsorption. ${ }^{210,211}$ Specifically, for the purpose of commercializing cell-based biomedical products in the regenerative medicine fields, it is necessary for stem cells to be cultured in a serum-free and animal-derived component free cell culture to ensure biological safety. Thus, to fulfill the simultaneous antiprotein non-fouling and cell adhesion requirements of tissue engineering, quite a few cell membrane bioinspired strategies have been developed in recent years.

As addressed above, traditional antifouling polymeric blocks, e.g., zwitterionic MPC, must be combined with other cell-adhesive units (with delicately controlled ratios) to be capably applied as tissue engineering scaffolds. ${ }^{212-215}$ For example, Wachiralarpphaithoon et al., reported a PMCP based porous hydrogel, acting as a 3D cell cultivation environment as cell/tissue matrices. ${ }^{216}$ In this system, the cytocompatible MPC was crosslinked with polyphosphoesters, which provided tunable degradation sites and promoted the adhesion and proliferation of mouse osteoblastic cells (MC3T3-E1). Collagen is another commonly used component endowing a cell-adhesive property to MPC-based polymers. ${ }^{193,217}$ For instance, Liu et al., prepared an interpenetrating network hydrogel using collagen and MPC. ${ }^{193}$ The hydrogel exhibited a well-enhanced mechanical strength and enzymatic stability. Meanwhile, although MPC is an anti-adhesive to cells, the reported hydrogel still exhibited good growth of the corneal cells and nerves owing to the cell friendly property of collagen. After a 12 month implantation of artificial corneas in mini-pigs, the hydrogel successfully induced the regeneration of the corneal tissue, tear film, and sensory nerves. Recently, an MPC block was also fabricated with benzoxaborole and catechol side-groups, separately, forming a self-healing hydrogel with a dynamic covalent for 3D cell encapsulation as a potential tissue engineering scaffold. $^{215}$

Another interesting and effective strategy has been reported to address this dilemma based on the previously described choline phosphate (CP), ${ }^{49}$ which was bioinspired by the structure of phosphate choline (PC) of a cell membrane. The $\mathrm{CP}^{218,219}$ or CP-based polymer ${ }^{50,51}$ modified surfaces can promote celladhesion through the CP-PC interaction while suppressing protein adsorption owing to their zwitterionic property (Fig. 11). The glass surface was first decorated by CP molecules through click reaction. $^{218,219}$ This significantly decreases the non-specific adsorption of proteins such as BSA, collagen, fibrinogen and serum $(p<0.01)$. Meanwhile, the CP-modified surface can 


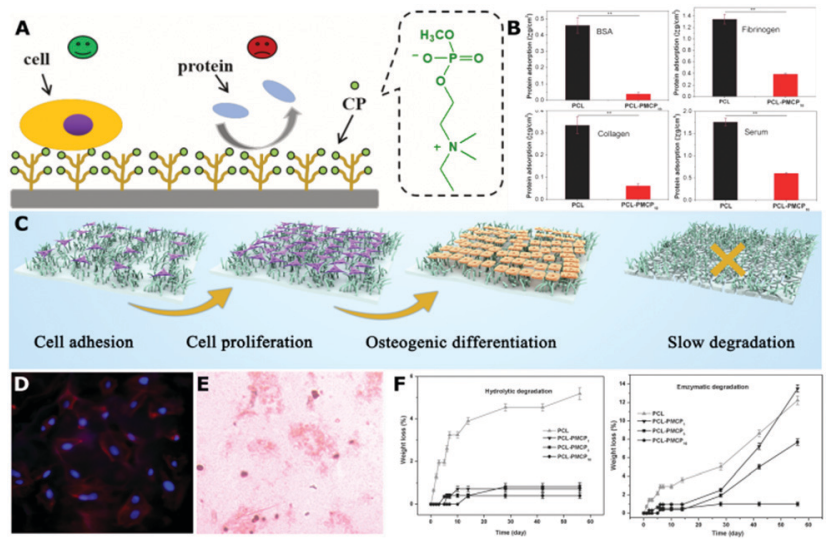

Fig. 11 (A) Schematic illustration of the CP polymer decorated surface with simultaneous protein-resistant and cell adhesive properties for tissue engineering. (B) Significantly reduced adsorption of various proteins (BSA, fibrinogen, collagen and serum) on the surface of PCL-PMCP $(* * p<0.01)$. (C) The illustration of adhesion, proliferation, osteogenic differentiation of BMSCs on the PCL-PMCP surface, also with slow degradation phenomenon. (D) Fluorescence image of BMSCs adhered on the PCL-PMCP film at 4 day $(200 \times)$. (E) Alizarin red staining assay showing the mineralized calcium nodules on the PCL-PMCP film at 21 day $(100 \times)$. (F) Slow hydrolytic/enzymatic degradation behaviors of PCL-PMCP films. Reproduced from ref. 50 and 51 with permission from American Chemical Society, Copyright 2017, and with permission from John Wiley and Sons, Copyright 2019

improve cell adhesion by almost 3 times more than the control sample while using human umbilical vein endothelial cells (HUVECs), HeLa, and L929 cells. It is important to note that the cell adhesion on the CP-modified surface under the serumfree condition shows no significant difference compared with that of serum-containing conditions during the initial $3 \mathrm{~h}$, indicating that the cell adhesion is mainly mediated by the CP-PC interaction instead of by the adsorbed ECM proteins. A comparative study between pMCP- and pMPC-modified surfaces also revealed their similar protein-resistant but very different cell-adhesive properties, although they had similar zwitterionic structures with only the headgroups of reverse orientations. ${ }^{220}$ Then, a multilayer CP polymer brush modified surface was prepared by introducing CP groups via post ring opening reaction on a surface pre-grafted with poly(dimethylamino)ethyl methacrylate (pDMAEMA) via surface-initiated atom-transfer radical polymerization (SI-ATRP). ${ }^{51}$ Although the percentage of CP group was only $24.6 \%$, the multilayer CP polymer modified surface still had around 5-times more CP groups than the monolayer surface, and thus it exhibited better protein resistance and cell adhesion. Recently, polycaprolactone (PCL), a typical biodegradable biomaterial used in tissue engineering, was successfully modified with poly[2-(methacryloyloxy)ethyl choline phosphate] (PMCP) via SI-ATRP. ${ }^{50}$ The hydrophobic PCL surface was modified into a hydrophilic state, and the non-specific protein adsorption was significantly decreased, e.g., up to 91.7\% for BSA. Bone marrow mesenchymal stem cells (BMSCs) adhered well on the surface of the PCL-PMCP films with good proliferation profiles. For PCL-PMCP films, the activity of alkaline phosphatase (ALP), and the expression of osteogenic differentiation genes (ALP, osteocalcin (OC), collagen I (COL-1), and Runx2) were significantly higher than that of the PCL film, even without osteogenesis-inducing supplements, indicating that PCL-PMCP can promote the differentiation of BMSCs into osteoblasts due to the phosphate group in the MCP molecule. Another interesting phenomenon was that the degradation of PCL-PMCP films was slowed down during the early stage although they showed a better hydrophilicity, exhibiting great potential particularly in hard tissue repair. Overall, the CP-based functional polymers have simultaneous proteinresistant and cell adhesive properties for the requirements of tissue engineering scaffolds.

Glycocalyx-like polymeric surfaces have been widely studied for tissue engineering scaffolds owing to their good biocompatibility, degradability, and anti-nonspecific adhesion of biomolecules and cells, while with a desirable adhesive interaction achieved by the specific interaction between cell membrane glycoprotein receptor molecules. ${ }^{221-223}$ For instance, the alginate-amino acid derivatives were synthesized to modify poly(lactic acid) (PLA) membranes. ${ }^{221}$ They could form a glycocalyx-like surface to promote chondrocyte adhesion and proliferation, i.e., chondrogenesis. Because PLA is a biocompatible material but lacks functional groups to realize cell adhesion for tissue engineering, this study provides a good solution to this problem. Meanwhile, 3D tissue engineering scaffolds have been widely investigated for the regeneration of tendon, bone, skin, blood vessels, and cartilage, etc. PCL is a common electrospun biodegradable material for these 3D scaffolds, but lacks cell-adhesive groups. Becer et al. synthesized a series of $\mathrm{A}_{2} \mathrm{~B}$-miktoarm copolymers with two PCL segments and one glycopolymer segment. After being electrospun to form a 3D membrane, the miktoarm copolymers with glucose units could effectively improve the cellular interaction with tenocytes (also enhanced their cell activity) and biocompatibility (Fig. 12). ${ }^{223}$ They further fabricated these glycopolymers into highly aligned electrospun membranes to offer patterning to guide the cell organization for tissue regeneration. ${ }^{224}$

Cell membrane coated materials may also be applied as tissue engineering scaffolds to promote the cell proliferation and their functions. For instance, Zhang et al. coated polymeric nanofibers (a mixture of polycaprolactone and poly-lysine) with pancreatic beta cell membranes. ${ }^{225}$ The resulting nanofibers exhibited important characteristics as that of the pancreatic beta cells, i.e., a strong interaction among beta cells in the pancreas. The proliferation rate and functions of the cultured beta cells on these nanofibers were significantly increased. Moreover, the glucose-dependent secretion of insulin from these cells are 5-fold higher than those cells cultured on unmodified nanofibers.

\subsection{Molecular recognition, diagnosis and imaging}

Cell membrane bioinspired polymers are widely applied to molecular recognition, and for disease diagnosis and imaging, mainly based on four types of strategies: (1) the cell membrane bioinspired polymers themselves have molecular recognition capabilities such as glycocalyx-like polymers that provide recognition sites for many molecular interaction processes and for the capturing 

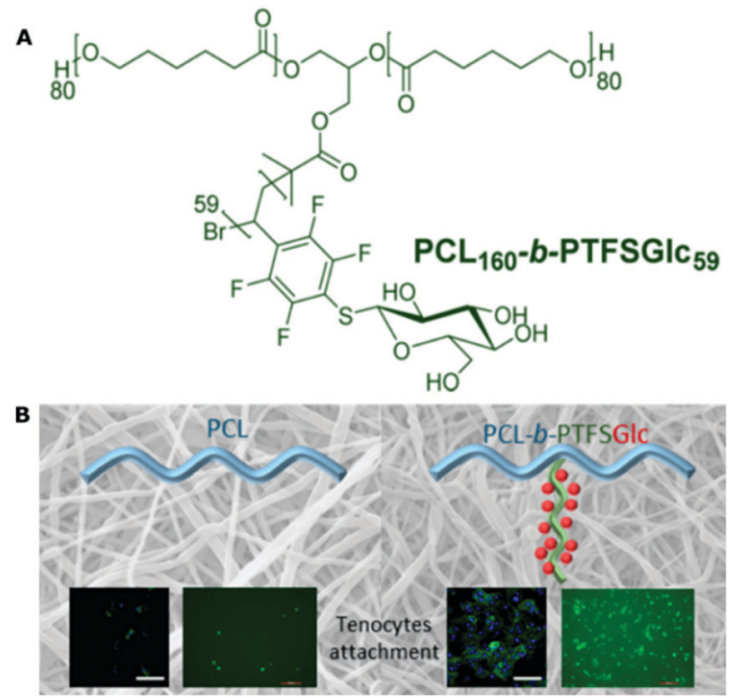

Fig. 12 (A) Chemical structure of the $\mathrm{A}_{2} \mathrm{~B}$-miktoarm glycopolymer with glucose moieties; (B) 3D electrospun membrane constructed by the glycopolymer for the cellular interaction with tenocytes. Reproduced from ref. 223 with permission from American Chemical Society, Copyright 2017.

of specific cells, ${ }^{17,115,119,207,226-233}$ as well as some specific interactions between proteins (e.g., C-reactive protein) and phosphorylcholine $;^{234-236}$ (2) The cell membrane bioinspired polymers provide an anti-fouling platform to resist the adsorption of nonspecific biomolecules, and other functional moieties are introduced to realize the recognition of specific biomolecules (e.g., biotin to avidin, prefoldin to amyloid $\beta$ oligomer, antibody to antigen, and peptide nucleic acid to DNA) or have a diagnosis/imaging function (e.g., red fluorescence, AIE, and CT/MR); $;^{26,90,103,237-247}$ (3) the polymeric materials are capable of detecting the physical/biological changes by the incorporated or biomimetic cell membrane channel proteins; $;^{28,47,136}$ (4) the natural or engineer cell membranes are applied to coat various polymeric materials to obtain cell membrane biomimetic disease diagnosis and imaging systems. ${ }^{248}$

The detection of lectin binding is extremely important for glycobiology and carbohydrate-based nanotechnologies. Kim et al. reported the recognition and monitoring of interfacial lectin binding with a very high sensitivity at the nanomolar level using immobilizing glycopolymers on the surface of a plasmonic field effect transistor (FET, Fig. 13). ${ }^{226}$ The glycopolymer immobilized FET can simulate the glycocalyx on the cell membrane to bind and detect lectin within a wide range of $10^{-10}$ to $10^{-4} \mathrm{M}$. After being functionalized with pendant D-glucose residue, it also exhibits a selective binding affinity toward glucose-binding lectins (concanavalin A, ConA), whereas the solution also contains various other lectins such as peanut agglutinin (PNA) and galanthus nivalis agglutinin (GNA). Most recently, Shan et al. also reported an interesting glycopolymer-brush interface for the rapid and naked-eye sensing of lectin (anti-)adhesion. ${ }^{119}$

Human C-reactive protein (CRP) is an annular pentameric protein, which is generated by hepatocytes in the liver. It is an inflammatory biomarker in blood plasma, and its circulation concentration can increase up to 1000-fold within 24-48 h after
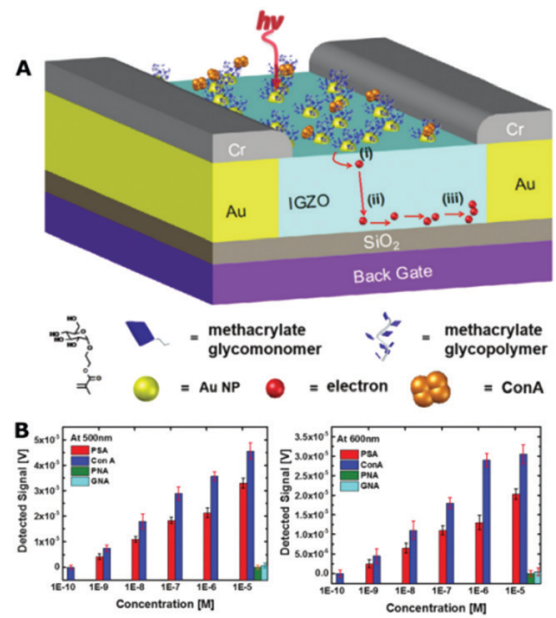

Fig. 13 (A) The Au nanoparticle-glycopolymer conjugates coated FET to monitor lectin (glucose-binding ConA in this work); (B) detected voltage signal for different target proteins at 500 and $600 \mathrm{~nm}$ excitations, and also at different protein concentrations. Reproduced from ref. 226 with permission from The Royal Society of Chemistry, Copyright 2016.

injury (the normal level is approximately $0.8 \mathrm{mg} \mathrm{L} \mathrm{L}^{-1}$ ). Because there is a well-known specific interaction between CRP and PC headgroups in the presence of calcium ions, quite a few studies have investigated the CPR-PC interaction mechanism, or fabricated various biosensors to monitor the circulation CRP levels using an MPC-based polymeric surface. ${ }^{234-236}$ For example, Shimada et al. prepared a thiolated MPC (MPC-SH) to modify the surface of nanowires through a self-assembly. The resulting nanowire can reduce the nonspecific biomolecule adsorption and specifically capture CRP in the presence of calcium ions. ${ }^{236}$ Recently, Jiang et al. reported an interesting copolymer film for the selective capture and purification of CRP in biological fluids (Fig. 14). ${ }^{234}$ The highly hydrophilic copolymer film was made from MPC, providing an anti-nonspecific protein adsorption characteristic and CRP affinity property, as well as a hydrophilic $N, N^{\prime}$-methylenebisacrylamide as a crosslinker. The film exhibits a high CRP recognition specificity and selectivity, e.g., in the SDS-PAGE image, all six other test proteins were detected in the washing fraction whereas only CRP was observed in the elution fraction, with the recovery of CRP at nearly $100 \%$. In addition, when the film was used to purify CRP from a rat serum with $185 \mathrm{mg} \mathrm{mL}^{-1}$ of total proteins, the purity of the obtained CRP was as high as $95 \%$. Meanwhile, the structural integrity and functionality of the CRP were maintained well during this procedure. This newly developed one-step CRP purification process from complex biological fluids can provide numerous advantages over traditional multi-step methods.

In a surface protein-imprinted magnetic microsphere biosensor based on polydopamine, a MPC polymer was further introduced using the ATRP method. The anti-protein nonspecific adsorption surface could significantly increase the imprinting factor from 1.53 to 5.74 , with only a slight decrease in adsorption of the target protein (BSA as a model, from $9.39 \mathrm{mg} \mathrm{g}^{-1}$ to $\left.8.26 \mathrm{mg} \mathrm{g}^{-1}\right) .{ }^{244}$ Most recently, Shi et al. designed a zwitterionic dendrimer, which was complexed using gadolinium(III) and 

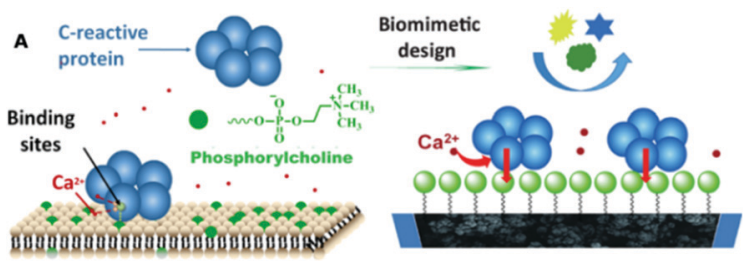

B

Anti-nonspecific adsorption

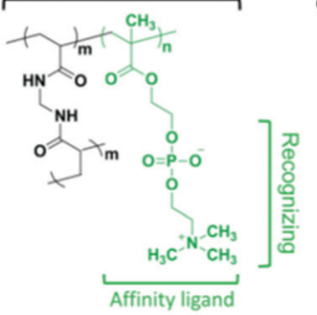

C

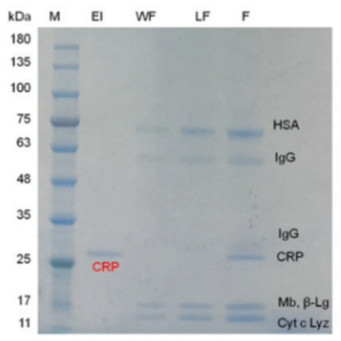

Fig. 14 (A) Schematic illustration of the cell membrane biomimetic polymeric film for the selective capture of $\mathrm{C}$-reactive protein by the specific PC-CRP interaction in the presence of calcium ions; (B) chemical structure of the polymeric film; (C) specificity and selectivity of the polymeric film for CRP using SDS-PAGE analysis. Reproduced from ref. 234 with permission from American Chemical Society, Copyright 2018

entrapped with gold nanoparticles as a dual mode contrast agent for the enhanced CT/MR imaging of lung cancer metastasis. ${ }^{90}$ In this report, a G5.0 dendrimer of poly(amidoamine) (PAMAM) was modified with several zwitterionic molecules including MPC, which helped construct a non-fouling surface to obtain improved pharmacokinetics by avoiding the clearance of the reticuloendothelial system. The half-decay time could be prolonged by up to $37.07 \mathrm{~h}$ using this strategy, along with a high $r_{1}$ relaxivity of $13.17 \mathrm{mM} \mathrm{s}^{-1}$.

Recently, Qing et al. reported a biomimetic ionic nanochannel that can be modulated using cyclic $3^{\prime}, 5^{\prime}$-adenosine monophosphate (cAMP). ${ }^{136}$ It was bioinspired by the natural $\mathrm{Na}^{+} / \mathrm{Ca}^{+}$ transmembrane behaviors modulated by the binding between cAMP and the cyclic nucleotide-gating channel proteins in the cell membrane. The arginine-based copolymer film can selectively adsorb cAMP by a specific hydrogen bonding, leading to a precisely cAMP-modulated dynamic gating performance. The sensitivity is extremely high $\left(10 \mathrm{pmol} \mathrm{L}^{-1}\right)$ for the fabrication of potential biosensors.

As previously discussed, cancer cell membrane coated nanoparticles have a specific targeting capability to homologous tumors. ${ }^{154,156,157}$ Recently, this strategy was also applied to the preparation of a cancer cell membrane coated nanoprobe for intravital tumor near-infrared (NIR) fluorescence imaging by Tian and coworkers (Fig. 15). ${ }^{248}$ The nanoparticle has a very interesting NIR-incoming and NIR-outgoing characteristic (720 $\mathrm{nm}$ emission upon $800 \mathrm{~nm}$ excitation), which was endowed by the conjugated polymer with specific two-photon absorption and Förster resonance energy transfer (FRET) properties. In this system, the cancer cell membrane provides excellent biocompatibility, selective targeting to homologous tumors, and an effective protection of the encapsulated photoactive polymers (i.e., retaining the fluorescent property in a physiological environment). In this way, the polymeric nanoprobe achieved

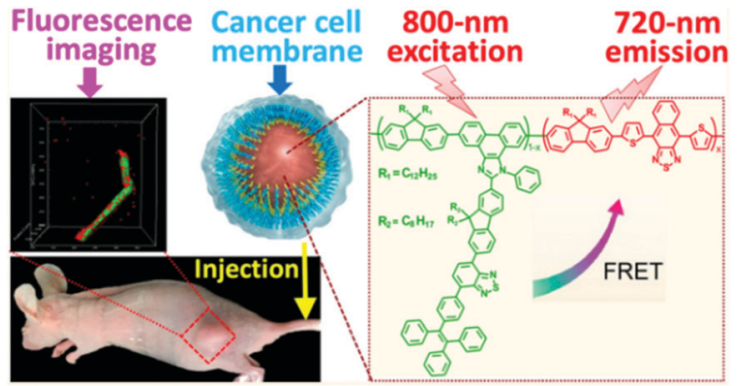

Fig. 15 The cancer cell membrane coated fluorescent nanoprobe constructed by the functional polymer with two-photon absorption and FRET characters, for the intravital NIR fluorescence imaging of tumors. Reproduced from ref. 248 with permission from American Chemical Society, Copyright 2018.

many excellent features such as a long-term structural integrity, high NIR fluorescence quantum yield, photostability (retaining $>90 \%$ after $30 \mathrm{~min}$ exposure to an $800 \mathrm{~nm}$ pulse laser), as well as a prolonged in vivo circulation time.

\subsection{Other biomedical applications}

There are many other biomedical applications using these cell membrane bioinspired functional polymers. For instance, soft contact lenses, which are usually made of poly(2-hydroxyethyl methacrylate) (poly[HEMA])-based hydrogels (for the disposable type) and high oxygen-permeable silicone hydrogels (for the continually wear type). As for the latter, phospholipid polymers containing MPC units have been utilized to improve the water wettability and biocompatibility, while retaining the high oxygen permeability. ${ }^{249}$ Another example was reported by Ziener et al. through the embedding of non-leaching silver nanoparticles into a poly(HEMA-co-MPC) film. The resulting film has combined antifouling (biopassive) and long-term antibacterial (bioactive) properties. The film exhibited a long-acting antifouling property

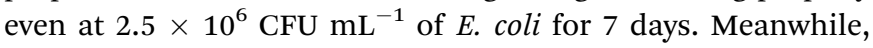
at a very low concentration of embedded $\mathrm{Ag}$ nanoparticle

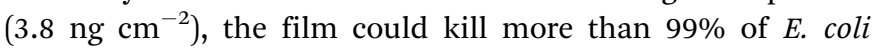
within $1 \mathrm{~h}$. The mechanism of the long-acting performances of both antifouling and antibacterial properties was attributed to the MPC structure as follows: MPC has strong hydrophilicity to form a hydration layer, which can facilitate the gradual dissolution of AgNPs into $\mathrm{Ag}^{+}$; and the $\mathrm{Ag}^{+}$could be retained with the hydration layer without leaching. ${ }^{250}$

Cell membrane bioinspired polymers also have great potential in the field of cell-based biomedical applications. In these applications such as cell therapy, cell-based assays, and regenerative medicine, it is necessary to use cells in different places and occasions, e.g., from a laboratory bench to a clinic bedside. However, the current cryopreservation of cells at $-196{ }^{\circ} \mathrm{C}$ in liquid nitrogen, or at $-80{ }^{\circ} \mathrm{C} /-20{ }^{\circ} \mathrm{C}$ for short distances and timeframes, is inconvenient for clinical operation. Thus, the hypothermic storage (i.e., $\left.1-35{ }^{\circ} \mathrm{C}\right)$ of the cells is more desirable. For this purpose, a multifunctional hydrogel was fabricated using an MPC-based polymer (Fig. 16). ${ }^{251}$ The zwitterionic MPC polymer formed a cell-membrane-biomimetic surface 
A
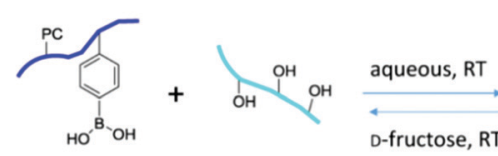

D-fructose, RT

PMBV

PVA

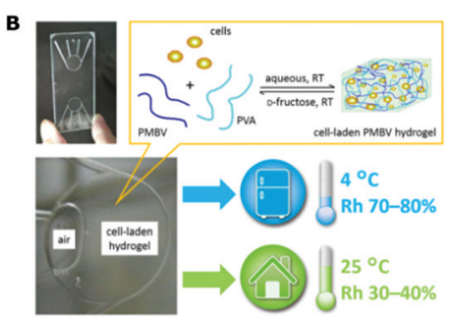

Fig. 16 Cell-membrane-biomimetic polymeric hydrogel in the microchip for the hypothermic storage of cells. (A) The formation and dissolution of the functional hydrogel. (B) The cell-laden hydrogel in the microchip. (C) The merged fluorescence image (live: green; dead: red) of L929 cells after being stored in the hydrogel within microchip for 16 days (scale bar: $100 \mu \mathrm{m})$. Reproduced from ref. 251 with permission from American Chemical Society, Copyright 2015.

with excellent cytocompatibility. A small amount of high molecular weight poly(vinyl alcohol) was also added to cross-link the MPC-based polymer between the boronic acid group and hydroxyl group. The boronic acid groups in the hydrogel could also provide the binding sites for a gelation-dissolution behavior, through the addition of low molecular weight sugar molecules such as D-galactose or D-fructose, for the reversible entrapment/ release of the cells. The cell-membrane-biomimetic polymeric hydrogel can thus be used for the spontaneous packaging and hypothermic storage of cells. Its storage capability was investigated using L929 cells for up to 16 days, and it was found that the cells can be stored at $4{ }^{\circ} \mathrm{C}$ for more than 1 week and at $25{ }^{\circ} \mathrm{C}$ for at least 4 days, with a high cell viability, cell membrane integrity and intracellular esterase activity. Finally, the cells released from the hydrogel after several days of storage still had good cell adhesion and proliferation capabilities under standard culture conditions of cells.

As discussed before, the cell membrane proteins usually serve as transport units. Kumar et al. reported a biomimetic channel-inserted lamellar membrane for ion selective separation. ${ }^{252}$ In this work, artificial and natural model channels, i.e., peptideappended pillar[5]arene (PAP5) and gramicidin A, respectively, were co-assembled with BAB block copolymers to form a multilayered lamellar membrane (Fig. 17). This nanofiltration membrane exhibited high selectivity and permeability for different ions, which could also be well controlled at the molecular level. It should be noted that this work provides general methods to prepare a channel-inserted membrane with synthetic or natural channels for various functions such as ion separation, biosensors and stimuli-sensitive nanodevices.

The oral healthcare of children and adolescents is challenged by their brushing habits and orthodontic fixed appliances. To prevent the demineralization of their teeth and decrease the occurrence of caries and white spots, topical fluoride treatments such as a fluoride varnish are widely applied. Most recently,

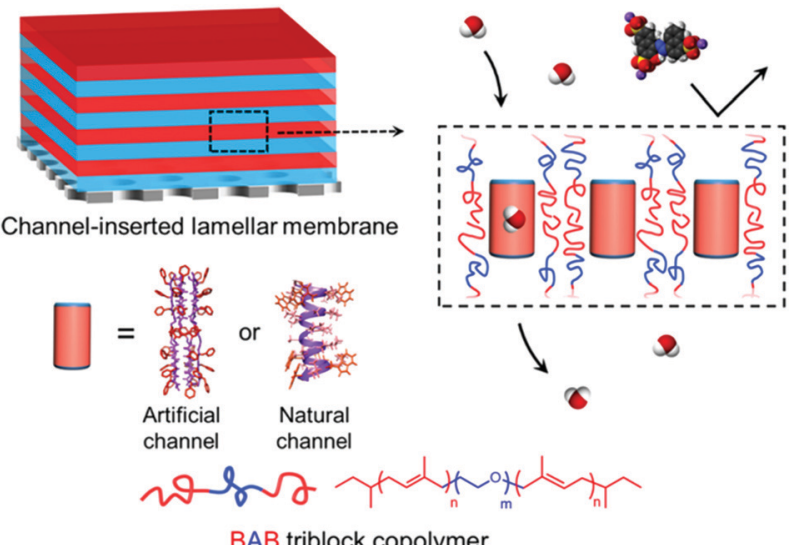

BAB triblock copolymer

Fig. 17 Schematic illustration of the bioinspired channel-inserted functional membrane. Reproduced from ref. 252 with permission from American Chemical Society, Copyright 2019.

MPC was added into a light-curable fluoride varnish to obtain a novel anti-fouling product to prevent tooth enamel demineralization. While at a low MPC concentration (3 $\mathrm{wt} \%)$, it can maintain the anti-demineralization property of the fluoride varnish, and also significantly reduce the adsorption of proteins. Meanwhile, it obviously decrease the adhesion of various bacteria such as Streptococcus mutans, Actinomyces naeslundii and Streptococcus sanguinis. Thus the MPC-containing fluoride varnish exhibits great potential for oral healthcare owing to its low bacterial adhesion and demineralization depth, as well as its high microhardness retention rate. ${ }^{253}$ This strategy may also be applied to quite a few polymeric materials for dental applications. ${ }^{3}$

\section{Challenges and future outlook}

Looking into the future, functional polymers bioinspired from cell membranes may have increasing applications in the biomedical field. Their interesting properties such as biocompatibility, non-specific protein/cell resistance, and specific biomolecules/cell recognition and interaction, endow them with desired and effective capabilities in drug/gene delivery, tissue engineering, implants, molecular recognition and other biomedical applications. However, most of these cell membrane bioinspired functional polymers are quite complex and require dedicated preparation procedures. Thus, how to scale up these functional polymers, i.e., improve their producibility to become clinic biomaterials or medical devices, remains a significant challenge. Meanwhile, there have only been a few reports ${ }^{186}$ on how to combine several cell membrane bioinspired units together and obtain a synergistic effect of their functions in biomedical applications, leaving a large challenge for material design strategies.

Several points might be helpful to address the above problems. First, more interdisciplinary cooperation with other basic science such as biology and medicine can obtain a more deeper understanding of the relationship among the chemical components, physical structure, and functions of cell membranes. Thus, it is possible to further simplify the bioinspired design of functional 
polymers and focus more on its key points. Second, these advanced polymerization (e.g., ATRP and interfacial polymerization $^{254}$ ) and preparation methods (e.g., LbL) should be taken into consideration when designing these functional polymers with a controllable molecular weight, molecular weight distribution, and functional groups. Finally, it is desirable to investigate their biocompatibility, bioactivity, and biofunctions to achieve the optimum performance in a large-scale model based on a cell membrane simulation, and thus accelerate the research process before potential use in medical products.

It is known that some MPC-based polymeric materials have been clinically applied after FDA authorization, such as the coatings of intravascular guide wires, intravascular stents, soft contact lenses, and oxygenators. ${ }^{81,255}$ As another example of recent progress in this field, Fujiwara et al. reported a singleblind, randomized, placebo-controlled and crossover clinical trial of an MPC polymer in $2019 .^{256}$ In this clinical trial using 20 healthy subjects, a 5\% MPC polymer mouthwash was applied during two treatment periods separated by a 2 -week washout period. As compared with the control group (PBS treated), the MPC-containing mouthwash significantly decreased the number of total bacteria (including oral streptococci), as well as the DNA amounts of the total bacteria and Fusobacterium nucleatum. Thus, the MPC polymer may become a real mouthwash product in the near future for controlling the oral microflora by suppressing the bacterial adhesion. Overall, we would anticipate an increasing number of cell membrane bioinspired functional polymers, e.g., zwitterionic polymers and some glycosylated polymers, will advance into clinic biomedical materials and devices after lengthy research.

\section{Conflicts of interest}

The authors declare no conflict of interest.

\section{Acknowledgements}

This work was supported by the National Natural Science Foundation of China (51925304 and 51803173), and Sichuan Province Science and Technology Innovation MiaoZi Funding (2018002).

\section{References}

1 V. B. Damodaran, D. Bhatnagar and N. S. Murthy, Biomedical polymers synthesis and processing, Springer Nature, 2016.

$2 \mathrm{~W}$. Wu, W. Wang and J. Li, Star polymers: advances in biomedical applications, Prog. Polym. Sci., 2015, 46, 55-85.

$3 \mathrm{X} . \mathrm{Xu}, \mathrm{L}$. He, B. Zhu, J. Li and J. Li, Advances in polymeric materials for dental applications, Polym. Chem., 2017, 8, 807-823.

4 M. C. G. Pella, M. K. Lima-Tenorio, E. T. Tenorio-Neto, M. R. Guilherme, E. C. Muniz and A. F. Rubira, Chitosan-based hydrogels: from preparation to biomedical applications, Carbohydr. Polym., 2018, 196, 233-245.

5 O. S. Fenton, K. N. Olafson, P. S. Pillai, M. J. Mitchell and R. Langer, Advances in Biomaterials for Drug Delivery, Adv. Mater., 2018, 30, 1705328.

6 J. Ding, J. Zhang, J. Li, D. Li, C. Xiao, H. Xiao, H. Yang, $\mathrm{X}$. Zhuang and X. Chen, Electrospun polymer biomaterials, Prog. Polym. Sci., 2019, 90, 1-34.

7 M. Nofar, D. Sacligil, P. J. Carreau, M. R. Kamal and M. C. Heuzey, Poly (lactic acid) blends: Processing, properties and applications, Int. J. Biol. Macromol., 2019, 125, 307-360.

8 A. Bordat, T. Boissenot, J. Nicolas and N. Tsapis, Thermoresponsive polymer nanocarriers for biomedical applications, Adv. Drug Delivery Rev., 2019, 138, 167-192.

9 M. Sohail, Mudassir, M. U. Minhas, S. Khan, Z. Hussain, M. de Matas, S. A. Shah, S. Khan, M. Kousar and K. Ullah, Natural and synthetic polymer-based smart biomaterials for management of ulcerative colitis: a review of recent developments and future prospects, Drug Delivery Transl. Res., 2019, 9, 595-614.

$10 \mathrm{~J} . \mathrm{Wu}, \mathrm{Y}$. Qu, Q. Yu and H. Chen, Gold nanoparticle layer: a versatile nanostructured platform for biomedical applications, Mater. Chem. Front., 2018, 2, 2175-2190.

11 Y. Ramot, M. Haim-Zada, A. J. Domb and A. Nyska, Biocompatibility and safety of PLA and its copolymers, Adv. Drug Delivery Rev., 2016, 107, 153-162.

12 X. Zhang, M. Liu, X. Zhang, F. Deng, C. Zhou, J. Hui, W. Liu and Y. Wei, Interaction of tannic acid with carbon nanotubes: enhancement of dispersibility and biocompatibility, Toxicol. Res., 2015, 4, 160-168.

13 S. F. Kiew, L. V. Kiew, H. B. Lee, T. Imae and L. Y. Chung, Assessing biocompatibility of graphene oxide-based nanocarriers: a review, J. Controlled Release, 2016, 226, 217-228.

14 S. Naahidi, M. Jafari, M. Logan, Y. Wang, Y. Yuan, H. Bae, B. Dixon and P. Chen, Biocompatibility of hydrogel-based scaffolds for tissue engineering applications, Biotechnol. Adv., 2017, 35, 530-544.

15 D. da Silva, M. Kaduri, M. Poley, O. Adir, N. Krinsky, J. ShainskyRoitman and A. Schroeder, Biocompatibility, biodegradation and excretion of polylactic acid (PLA) in medical implants and theranostic systems, Chem. Eng. J., 2018, 340, 9-14.

16 C. Sanchez, H. Arribart and M. M. R. Guille, Biomimetism and bioinspiration as tools for the design of innovative materials and systems, Nat. Mater., 2005, 4, 277-288.

17 P. Bojarova and V. Kren, Sugared biomaterial binding lectins: achievements and perspectives, Biomater. Sci., 2016, 4, 1142-1160.

18 A. Parodi, R. Molinaro, M. Sushnitha, M. Evangelopoulos, J. O. Martinez, N. Arrighetti, C. Corbo and E. Tasciotti, Bioinspired engineering of cell- and virus-like nanoparticles for drug delivery, Biomaterials, 2017, 147, 155-168.

19 F. Bouville, E. Maire, S. Meille, B. Van de Moortele, A. J. Stevenson and S. Deville, Strong, tough and stiff bioinspired ceramics from brittle constituents, Nat. Mater., 2014, 13, 508-514. 
20 U. G. Wegst, H. Bai, E. Saiz, A. P. Tomsia and R. O. Ritchie, Bioinspired structural materials, Nat. Mater., 2015, 14, 23-36.

21 Y. Kim, A. Chortos, W. Xu, Y. Liu, J. Y. Oh, D. Son, J. Kang, A. M. Foudeh, C. Zhu, Y. Lee, S. Niu, J. Liu, R. Pfattner, Z. Bao and T. W. Lee, A bioinspired flexible organic artificial afferent nerve, Science, 2018, 360, 998-1003.

22 Z. Zhang, L. Wen and L. Jiang, Bioinspired smart asymmetric nanochannel membranes, Chem. Soc. Rev., 2018, 47, 322-356.

23 J. R. Clegg, A. M. Wagner, S. R. Shin, S. Hassan, A. Khademhosseini and N. A. Peppas, Modular fabrication of intelligent material-tissue interfaces for bioinspired and biomimetic devices, Prog. Mater. Sci., 2019, 106, 100589.

24 C. Alvarez-Lorenzo and A. Concheiro, Bioinspired drug delivery systems, Curr. Opin. Biotechnol., 2013, 24, 1167-1173.

25 H. Michelle Grandin, O. Guillaume-Gentil, T. Zambelli, M. Mayer, J. Houghtaling, C. G. Palivan, M. Textor and F. Hook, Bioinspired, nanoscale approaches in contemporary bioanalytics (Review), Biointerphases, 2018, 13, 040801.

26 R. Matsuno and K. Ishihara, Integrated functional nanocolloids covered with artificial cell membranes for biomedical applications, Nano Today, 2011, 6, 61-74.

27 J. Zhao, X. Zhao, Z. Jiang, Z. Li, X. Fan, J. Zhu, H. Wu, Y. Su, D. Yang, F. Pan and J. Shi, Biomimetic and bioinspired membranes: Preparation and application, Prog. Polym. Sci., 2014, 39, 1668-1720.

28 C. G. Palivan, R. Goers, A. Najer, X. Zhang, A. Car and W. Meier, Bioinspired polymer vesicles and membranes for biological and medical applications, Chem. Soc. Rev., 2016, 45, 377-411.

29 G. Yang, S. Chen and J. Zhang, Bioinspired and Biomimetic Nanotherapies for the Treatment of Infectious Diseases, Front. Pharmacol., 2019, 10, 751.

30 J. Liu, T. Cui and Y. Ding, Biomimetic gold nanoparticles, Compos. Commun., 2018, 10, 209-216.

31 A. Pasto, F. Giordano, M. Evangelopoulos, A. Amadori and E. Tasciotti, Cell membrane protein functionalization of nanoparticles as a new tumor-targeting strategy, Clin. Transl. Med., 2019, 8, 8.

32 X. Yang, H. Shang, C. Ding and J. Li, Recent developments and applications of bioinspired dendritic polymers, Polym. Chem., 2015, 6, 668-680.

33 C. Ding, Z. Chen and J. Li, From molecules to macrostructures: recent development of bioinspired hard tissue repair, Biomater. Sci., 2017, 5, 1435-1449.

34 X. Yang, F. Huang, X. Xu, Y. Liu, C. Ding, K. Wang, A. Guo, W. Li and J. Li, Bioinspired from Salivary Acquired Pellicle: A Multifunctional Coating for Biominerals, Chem. Mater., 2017, 29, 5663-5670.

35 X. Yang, Z. Li, H. Xiao, N. Wang, Y. Li, X. Xu, Z. Chen, H. Tan and J. Li, A Universal and Ultrastable Mineralization Coating Bioinspired from Biofilms, Adv. Funct. Mater., 2018, 28, 1802730.

36 S. Yao, B. Jin, Z. Liu, C. Shao, R. Zhao, X. Wang and R. Tang, Biomineralization: From Material Tactics to Biological Strategy, Adv. Mater., 2017, 29, 1605903.
37 S. Vignolini and N. Bruns, Bioinspiration Across All Length Scales of Materials, Adv. Mater., 2018, 30, e1801687.

38 L. A. Berglund and I. Burgert, Bioinspired Wood Nanotechnology for Functional Materials, Adv. Mater., 2018, 30, e1704285.

39 B. D. Wilts, X. Sheng, M. Holler, A. Diaz, M. GuizarSicairos, J. Raabe, R. Hoppe, S. H. Liu, R. Langford, O. D. Onelli, D. Chen, S. Torquato, U. Steiner, C. G. Schroer, S. Vignolini and A. Sepe, Evolutionary-Optimized Photonic Network Structure in White Beetle Wing Scales, Adv. Mater., 2018, 30, e1702057.

40 G. Isapour and M. Lattuada, Bioinspired StimuliResponsive Color-Changing Systems, Adv. Mater., 2018, 30, e1707069.

41 T. B. H. Schroeder, J. Houghtaling, B. D. Wilts and M. Mayer, It's Not a Bug, It's a Feature: Functional Materials in Insects, Adv. Mater., 2018, 30, e1705322.

42 E. Kizilkan and S. N. Gorb, Combined Effect of the Microstructure and Underlying Surface Curvature on the Performance of Biomimetic Adhesives, Adv. Mater., 2018, 30, e1704696.

43 A. P. C. Almeida, J. P. Canejo, S. N. Fernandes, C. Echeverria, P. L. Almeida and M. H. Godinho, Cellulose-Based Biomimetics and Their Applications, Adv. Mater., 2018, 30, e1703655.

44 R. Kautz, D. D. Ordinario, V. Tyagi, P. Patel, T. N. Nguyen and A. A. Gorodetsky, Cephalopod-Derived Biopolymers for Ionic and Protonic Transistors, Adv. Mater., 2018, 30, e1704917.

45 G. van Meer, D. R. Voelker and G. W. Feigenson, Membrane lipids: where they are and how they behave, Nat. Rev. Mol. Cell Biol., 2008, 9, 112-124.

46 N. B. Holland, Y. Qiu, M. Ruegsegger and R. E. Marchant, Biomimetic engineering of non-adhesive glycocalyx-like surfaces using oligosaccharide surfactant polymers, Nature, 1998, 392, 799-801.

47 M. Garni, S. Thamboo, C. A. Schoenenberger and C. G. Palivan, Biopores/membrane proteins in synthetic polymer membranes, Biochim. Biophys. Acta, Biomembr., 2017, 1859, 619-638.

48 K. Ishihara and M. Takai, Bioinspired interface for nanobiodevices based on phospholipid polymer chemistry, J. $R$. Soc., Interface, 2009, 6, S279-S291.

49 X. Yu, Z. Liu, J. Janzen, I. Chafeeva, S. Horte, W. Chen, R. K. Kainthan, J. N. Kizhakkedathu and D. E. Brooks, Polyvalent choline phosphate as a universal biomembrane adhesive, Nat. Mater., 2012, 11, 468-476.

50 X. Chen, Z. Lin, Y. Feng, H. Tan, X. Xu, J. Luo and J. Li, Zwitterionic PMCP-Modified Polycaprolactone Surface for Tissue Engineering: Antifouling, Cell Adhesion Promotion, and Osteogenic Differentiation Properties, Small, 2019, 15, 1903784.

51 X. Chen, M. Yang, B. Liu, Z. Li, H. Tan and J. Li, Multilayer Choline Phosphate Molecule Modified Surface with Enhanced Cell Adhesion but Resistance to Protein Adsorption, Langmuir, 2017, 33, 8295-8301.

52 Z. Zhang, X. Y. Kong, K. Xiao, G. Xie, Q. Liu, Y. Tian, H. Zhang, J. Ma, L. Wen and L. Jiang, A Bioinspired 
Multifunctional Heterogeneous Membrane with Ultrahigh Ionic Rectification and Highly Efficient Selective Ionic Gating, Adv. Mater., 2016, 28, 144-150.

53 Y. Wang, K. Zhang, X. Qin, T. Li, J. Qiu, T. Yin, J. Huang, S. McGinty, G. Pontrelli, J. Ren, Q. Wang, W. Wu and G. Wang, Biomimetic Nanotherapies: Red Blood Cell Based Core-Shell Structured Nanocomplexes for Atherosclerosis Management, Adv. Sci., 2019, 6, 1900172.

54 M. X. Hu, Y. Fang and Z. K. Xu, Glycosylated membranes: a promising biomimetic material, J. Appl. Polym. Sci., 2014, 131, 39658-39670.

55 J. W. Szostak, D. P. Bartel and P. L. Luisi, Advances in directed evolution and membrane biophysics make the synthesis of simple living cells, if not yet foreseeable reality, an imaginable goal. Overcoming the many scientific challenges along the way will deepen our understanding of the essence of cellular life and its origin on Earth, Nature, 2001, 409, 387-390.

56 R. J. Peters, M. Marguet, S. Marais, M. W. Fraaije, J. C. van Hest and S. Lecommandoux, Cascade reactions in multicompartmentalized polymersomes, Angew. Chem., Int. Ed., 2014, 53, 146-150.

57 X. Huang, A. J. Patil, M. Li and S. Mann, Design and construction of higher-order structure and function in proteinosome-based protocells, J. Am. Chem. Soc., 2014, 136, 9225-9234.

58 S. Thamboo, A. Najer, A. Belluati, C. Planta, D. Wu, I. Craciun, W. Meier and C. G. Palivan, Mimicking Cellular Signaling Pathways within Synthetic Multicompartment Vesicles with Triggered Enzyme Activity and Induced Ion Channel Recruitment, Adv. Funct. Mater., 2019, 29, 1904267.

59 V. Abetz, T. Brinkmann, M. Dijkstra, K. Ebert, D. Fritsch, K. Ohlrogge, D. Paul, K. V. Peinemann, S. Pereira-Nunes, N. Scharnagl and M. Schossig, Developments in Membrane Research: from Material via Process Design to Industrial Application, Adv. Eng. Mater., 2006, 8, 328-358.

60 Y. Lu, J. Huskens, W. Pang and X. Duan, Hypersonic poration of supported lipid bilayers, Mater. Chem. Front., 2019, 3, 782-790.

61 R. J. Bose, B. J. Kim, Y. Arai, I. B. Han, J. J. Moon, R. Paulmurugan, H. Park and S. H. Lee, Bioengineered stem cell membrane functionalized nanocarriers for therapeutic targeting of severe hindlimb ischemia, Biomaterials, 2018, 185, 360-370.

62 H. P. Pace, J. K. Hannestad, A. Armonious, M. Adamo, B. Agnarsson, A. Gunnarsson, S. Micciulla, P. Sjovall, Y. Gerelli and F. Hook, Structure and Composition of Native Membrane Derived Polymer-Supported Lipid Bilayers, Anal. Chem., 2018, 90, 13065-13072.

63 X. Zhen, P. Cheng and K. Pu, Recent Advances in Cell Membrane-Camouflaged Nanoparticles for Cancer Phototherapy, Small, 2019, 15, e1804105.

64 E. S. Hara, M. Okada, T. Kuboki, T. Nakano and T. Matsumoto, Rapid bioinspired mineralization using cell membrane nanofragments and alkaline milieu, J. Mater. Chem. B, 2018, 6, 6153-6161.
65 T. Li, H. Dong, C. Zhang and R. Mo, Cell-based drug delivery systems for biomedical applications, Nano Res., 2018, 11, 5240-5257.

66 M. Chen, M. Chen and J. He, Cancer cell membrane cloaking nanoparticles for targeted co-delivery of doxorubicin and PD-L1 siRNA, Artif. Cells, Nanomed., Biotechnol., 2019, 47, 1635-1641.

67 S. Malhotra, S. Dumoga, P. Sirohi and N. Singh, Red Blood Cells-Derived Vesicles for Delivery of Lipophilic Drug Camptothecin, ACS Appl. Mater. Interfaces, 2019, 11, 22141-22151.

68 X. Dong, J. Gao, C. Y. Zhang, C. Hayworth, M. Frank and Z. Wang, Neutrophil Membrane-Derived Nanovesicles Alleviate Inflammation To Protect Mouse Brain Injury from Ischemic Stroke, ACS Nano, 2019, 13, 1272-1283.

69 J. Xue, Z. Zhao, L. Zhang, L. Xue, S. Shen, Y. Wen, Z. Wei, L. Wang, L. Kong, H. Sun, Q. Ping, R. Mo and C. Zhang, Neutrophil-mediated anticancer drug delivery for suppression of postoperative malignant glioma recurrence, Nat. Nanotechnol., 2017, 12, 692-700.

70 A. Salmaggi, M. Eoli, S. Frigerio, A. Silvani, M. Gelati, E. Corsini, G. Broggi and A. Boiardi, Intracavitary VEGF, bFGF, IL-8, IL-12 levels in primary and recurrent malignant glioma, J. Neuro-Oncol., 2003, 62, 297-303.

71 R. van den Hurk and S. Evoy, A Review of Membrane-Based Biosensors for Pathogen Detection, Sensors, 2015, 15, 14045-14078.

72 A. Hasan, M. Nurunnabi, M. Morshed, A. Paul, A. Polini, T. Kuila, M. Al Hariri, Y. K. Lee and A. A. Jaffa, Recent advances in application of biosensors in tissue engineering, BioMed Res. Int., 2014, 2014, 307519.

73 L. Qiu, T. Zhang, J. Jiang, C. Wu, G. Zhu, M. You, X. Chen, L. Zhang, C. Cui, R. Yu and W. Tan, Cell membraneanchored biosensors for real-time monitoring of the cellular microenvironment, J. Am. Chem. Soc., 2014, 136, 13090-13093.

74 H. Koo, S. Lee, J. H. Na, S. H. Kim, S. K. Hahn, K. Choi, I. C. Kwon, S. Y. Jeong and K. Kim, Bioorthogonal copper-free click chemistry in vivo for tumor-targeted delivery of nanoparticles, Angew. Chem., Int. Ed., 2012, 51, 11836-11840.

75 L. Tang, Q. Yin, Y. Xu, Q. Zhou, K. Cai, J. Yen, L. W. Dobrucki and J. Cheng, Bioorthogonal Oxime Ligation Mediated In Vivo Cancer Targeting, Chem. Sci., 2015, 6, 2182-2186.

76 P. Shi, N. Zhao, J. Coyne and Y. Wang, DNA-templated synthesis of biomimetic cell wall for nanoencapsulation and protection of mammalian cells, Nat. Commun., 2019, 10, 2223.

77 N. Li, Z. Huang, Z. Ye, X. Zhang, L. Chen and Y. Xiao, Total membrane lipid assay (MLA): simple and practical quantification of exosomes based on efficient membrane-specific dyes unaffected by proteins, Mater. Chem. Front., 2018, 2, 2130-2139.

78 N. Nakabayashi and D. F. Williams, Preparation of nonthrombogenic materials using 2-methacryloyloxyethyl phosphorylcholine, Biomaterials, 2003, 24, 2431-2435. 
79 S. Monge, B. Canniccioni, A. Graillot and J. J. Robin, Phosphorus-containing polymers: a great opportunity for the biomedical field, Biomacromolecules, 2011, 12, 1973-1982.

80 M. Gong, Y. B. Wang, M. Li, B. H. Hu and Y. K. Gong, Fabrication and hemocompatibility of cell outer membrane mimetic surfaces on chitosan by layer by layer assembly with polyanion bearing phosphorylcholine groups, Colloids Surf., B, 2011, 85, 48-55.

81 T. Moro, Y. Takatori, K. Ishihara, T. Konno, Y. Takigawa, T. Matsushita, U. I. Chung, K. Nakamura and H. Kawaguchi, Surface grafting of artificial joints with a biocompatible polymer for preventing periprosthetic osteolysis, Nat. Mater., 2004, 3, 829-836.

82 K. Bito, T. Hasebe, S. Maegawa, T. Kitagawa, T. Matsumoto, T. Suzuki and A. Hotta, Micropatterning of a 2-methacryloyloxyethyl phosphorylcholine polymer surface by hydrogenated amorphous carbon thin films for endothelialization and antithrombogenicity, Acta Biomater., 2019, 87, 187-196.

83 H. Mackova, Z. Plichta, H. Hlidkova, O. Sedlacek, R. Konefal, Z. Sadakbayeva, M. Duskova-Smrckova, D. Horak and S. Kubinova, Reductively Degradable Poly(2-hydroxyethyl methacrylate) Hydrogels with Oriented Porosity for Tissue Engineering Applications, ACS Appl. Mater. Interfaces, 2017, 9, 10544-10553.

84 Y. Iwasaki, E. Tabata, K. Kurita and K. Akiyoshi, Selective Cell Attachment to a Biomimetic Polymer Surface through the Recognition of Cell-Surface Tags, Bioconjugate Chem., 2005, 16, 567-575.

85 Y. Iwasaki, H. Maie and K. Akiyoshi, Cell-Specific Delivery of Polymeric Nanoparticles to Carbohydrate-Tagging Cells, Biomacromolecules, 2007, 8, 3162-3168.

86 K. Fukazawa and K. Ishihara, Fabrication of a cell-adhesive protein imprinting surface with an artificial cell membrane structure for cell capturing, Biosens. Bioelectron., 2009, 25, 609-614.

87 W. Feng, X. Gao, G. McClung, S. Zhu, K. Ishihara and J. L. Brash, Methacrylate polymer layers bearing poly(ethylene oxide) and phosphorylcholine side chains as non-fouling surfaces: in vitro interactions with plasma proteins and platelets, Acta Biomater., 2011, 7, 3692-3699.

88 S. Kakinoki, Y. Sakai, T. Takemura, N. Hanagata, T. Fujisato, K. Ishihara and T. Yamaoka, Gene chip/PCRarray analysis of tissue response to 2-methacryloyloxyethyl phosphorylcholine (MPC) polymer surfaces in a mouse subcutaneous transplantation system, J. Biomater. Sci., Polym. Ed., 2014, 25, 1658-1672.

89 B. L. Wang, T. W. Jin, Y. M. Han, C. H. Shen, Q. Li, Q. K. Lin and $\mathrm{H}$. Chen, Bio-inspired terpolymers containing dopamine, cations and MPC: a versatile platform to construct a recycle antibacterial and antifouling surface, J. Mater. Chem. B, 2015, 3, 5501-5510.

90 J. Liu, Z. Xiong, J. Zhang, C. Peng, B. Klajnert-Maculewicz, M. Shen and X. Shi, Zwitterionic Gadolinium(III)-Complexed Dendrimer-Entrapped Gold Nanoparticles for Enhanced Computed Tomography/Magnetic Resonance Imaging of
Lung Cancer Metastasis, ACS Appl. Mater. Interfaces, 2019, 11, 15212-15221.

91 M. Kobayashi, Y. Terayama, N. Hosaka, M. Kaido, A. Suzuki, N. Yamada, N. Torikai, K. Ishihara and A. Takahara, Friction behavior of high-density poly(2methacryloyloxyethyl phosphorylcholine) brush in aqueous media, Soft Matter, 2007, 3, 740-746.

92 Y.-B. Wang, M. Gong, S. Yang, K. Nakashima and Y.-K. Gong, Hemocompatibility and film stability improvement of crosslinkable MPC copolymer coated polypropylene hollow fiber membrane, J. Membr. Sci., 2014, 452, 29-36.

93 S. H. Ye, D. T. Arazawa, Y. Zhu, V. Shankarraman, A. D. Malkin, J. D. Kimmel, L. J. Gamble, K. Ishihara, W. J. Federspiel and W. R. Wagner, Hollow fiber membrane modification with functional zwitterionic macromolecules for improved thromboresistance in artificial lungs, Langmuir, 2015, 31, 2463-2471.

94 S. H. Chen, Y. Chang and K. Ishihara, Reduced Blood Cell Adhesion on Polypropylene Substrates through a Simple Surface Zwitterionization, Langmuir, 2017, 33, 611-621.

95 K. Ishihara, R. Takayama, N. Nakabayashi, K. Fukumoto and J. Aodi, Improvement of blood compatibility on cellulose dialysis membrane, Biomaterials, 1992, 13, 235-239.

96 C. Wang, A. Javadi, M. Ghaffari and S. Gong, A pH-sensitive molecularly imprinted nanospheres/hydrogel composite as a coating for implantable biosensors, Biomaterials, 2010, 31, 4944-4951.

97 M. Gong, Y. Dang, Y. B. Wang, S. Yang, F. M. Winnik and Y. K. Gong, Cell membrane mimetic films immobilized by synergistic grafting and crosslinking, Soft Matter, 2013, 9, 4501-4508.

98 H. Qi, L. Yang, X. Li, X. Sun, J. Zhao, X. Hou, Z. Li, X. Yuan, Z. Cui and X. Yang, Systemic administration of enzymeresponsive growth factor nanocapsules for promoting bone repair, Biomater. Sci., 2019, 7, 1675-1685.

99 J. Watanabe and K. Ishihara, Establishing ultimate biointerfaces covered with phosphorylcholine groups, Colloids Surf., B, 2008, 65, 155-165.

100 R. Matsuno and K. Ishihara, Structure and Surface Properties of High-density Polyelectrolyte Brushes at the Interface of Aqueous Solution, Macromol. Symp., 2009, 279, 125-131.

101 M. Kobayashi, H. Yamaguchi, Y. Terayama, Z. Wang, K. Ishihara, M. Hino and A. Takahara, Molecular-Integrated Phospholipid Polymer Nanoparticles with Highly Biofunctionality, Macromol. Symp., 2009, 279, 79-87.

102 L. Li, Y. Song, J. He, M. Zhang, J. Liu and P. Ni, Zwitterionic shielded polymeric prodrug with folate-targeting and $\mathrm{pH}$ responsiveness for drug delivery, J. Mater. Chem. B, 2019, 7, 786-795.

103 Y. Liu, L. Mao, S. Yang, M. Liu, H. Huang, Y. Wen, F. Deng, Y. Li, X. Zhang and Y. Wei, Synthesis and biological imaging of fluorescent polymeric nanoparticles with AIE feature via the combination of RAFT polymerization and post-polymerization modification, Dyes Pigm., 2018, 158, 79-87. 
104 B. Zhu, S. C. Luo, H. Zhao, H. A. Lin, J. Sekine, A. Nakao, C. Chen, Y. Yamashita and H. H. Yu, Large enhancement in neurite outgrowth on a cell membrane-mimicking conducting polymer, Nat. Commun., 2014, 5, 4523.

105 X. Yu, X. Yang, S. Horte, J. N. Kizhakkedathu and D. E. Brooks, ATRP synthesis of poly(2-(methacryloyloxy)ethyl choline phosphate): a multivalent universal biomembrane adhesive, Chem. Commun., 2013, 49, 6831-6833.

106 Q. Yang, C. Kaul and M. Ulbricht, Anti-nonspecific protein adsorption properties of biomimetic glycocalyx-like glycopolymer layers: effects of glycopolymer chain density and protein size, Langmuir, 2010, 26, 5746-5752.

107 L. Su, Y. Zhao, G. Chen and M. Jiang, Polymeric vesicles mimicking glycocalyx (PV-Gx) for studying carbohydrateprotein interactions in solution, Polym. Chem., 2012, 3, 1560.

108 J. Huang, C. Bonduelle, J. Thevenot, S. Lecommandoux and A. Heise, Biologically active polymersomes from amphiphilic glycopeptides, J. Am. Chem. Soc., 2012, 134, 119-122.

109 P. Sun, Y. He, M. Lin, Y. Zhao, Y. Ding, G. Chen and M. Jiang, Glyco-regioisomerism Effect on Lectin-Binding and Cell-Uptake Pathway of Glycopolymer-Containing Nanoparticles, ACS Macro Lett., 2013, 3, 96-101.

110 J. Zhu, F. Yan, Z. Guo and R. E. Marchant, Surface modification of liposomes by saccharides: vesicle size and stability of lactosyl liposomes studied by photon correlation spectroscopy, J. Colloid Interface Sci., 2005, 289, 542-550.

111 L. E. Wilkins, D. J. Phillips, R. C. Deller, G. L. Davies and M. I. Gibson, Synthesis and characterisation of glucosefunctional glycopolymers and gold nanoparticles: study of their potential interactions with ovine red blood cells, Carbohydr. Res., 2015, 405, 47-54.

112 A. David, P. Kopeckova, A. Rubinstein and J. Kopecek, Enhanced Biorecognition and Internalization of HPMA Copolymers Containing Multiple or Multivalent Carbohydrate Side-Chains by Human Hepatocarcinoma Cells, Bioconjugate Chem., 2001, 12, 890-899.

113 M. A. Moretton, E. Bernabeu, E. Grotz, L. Gonzalez, M. Zubillaga and D. A. Chiappetta, A glucose-targeted mixed micellar formulation outperforms Genexol in breast cancer cells, Eur. J. Pharm. Biopharm., 2017, 114, 305-316.

114 Y. Chen, Z. Tan, W. Wang, Y. Y. Peng and R. Narain, Injectable, Self-Healing, and Multi-Responsive Hydrogels via Dynamic Covalent Bond Formation between Benzoxaborole and Hydroxyl Groups, Biomacromolecules, 2019, 20, 1028-1035.

115 U. Y. Lau, S. S. Saxer, J. Lee, E. Bat and H. D. Maynard, Direct Write Protein Patterns for Multiplexed Cytokine Detection from Live Cells Using Electron Beam Lithography, ACS Nano, 2016, 10, 723-729.

116 A. Battigelli, J. H. Kim, D. C. Dehigaspitiya, C. Proulx, E. J. Robertson, D. J. Murray, B. Rad, K. Kirshenbaum and R. N. Zuckermann, Glycosylated Peptoid Nanosheets as a Multivalent Scaffold for Protein Recognition, ACS Nano, 2018, 12, 2455-2465.
117 J. K. Ajish, K. S. Ajish Kumar, A. Ruhela, M. Subramanian, A. D. Ballal and M. Kumar, AIE based fluorescent self assembled glycoacrylamides for E.coli detection and cell imaging, Sens. Actuators, B, 2018, 255, 1726-1734.

118 M. N. Zhou, C. S. Delaveris, J. R. Kramer, J. A. Kenkel, E. G. Engleman and C. R. Bertozzi, $\mathrm{N}$-Carboxyanhydride Polymerization of Glycopolypeptides That Activate AntigenPresenting Cells through Dectin-1 and Dectin-2, Angew. Chem., Int. Ed., 2018, 57, 3137-3142.

119 J. Li, X. Y. Tian, L. P. Zong, Q. Zhang, X. J. Zhang, R. Marks, S. Cosnier and D. Shan, Uniform and Easy-To-Prepare Glycopolymer-Brush Interface for Rapid Protein (Anti-)Adhesion Sensing, ACS Appl. Mater. Interfaces, 2019, 11, 32366-32372.

120 Y. Terada, Y. Hoshino and Y. Miura, Glycopolymers Mimicking GM1 Gangliosides: Cooperativity of Galactose and Neuraminic Acid for Cholera Toxin Recognition, Chem. - Asian J., 2019, 14, 1021-1027.

121 A. Camaleno de la Calle, C. Gerke, X. J. Chang, A. Grafmuller, L. Hartmann and S. Schmidt, Multivalent Interactions of Polyamide Based Sequence-Controlled Glycomacromolecules with Concanavalin A, Macromol. Biosci., 2019, 19, e1900033.

122 D. J. Siegwart, J. K. Oh and K. Matyjaszewski, ATRP in the design of functional materials for biomedical applications, Prog. Polym. Sci., 2012, 37, 18-37.

123 S. Fukui, T. Feizi, C. Galustian, A. M. Lawson and W. Chai, Oligosaccharide microarrays for high-throughput detection and specificity assignments of carbohydrate-protein interactions, Nat. Biotechnol., 2002, 20, 1011-1017.

124 H. F. Lu, W. S. Lim, J. Wang, Z.-Q. Tang, P.-C. Zhang, K. W. Leong, S. M. Chia, H. Yu and H.-Q. Mao, Galactosylated PVDF membrane promotes hepatocyte attachment and functional maintenance, Biomaterials, 2003, 24, 4893-4903.

125 K. Esaki, S. Yokota, S. Egusa, Y. Okutani, Y. Ogawa, T. Kitaoka, M. Goto and H. Wariishi, Preparation of Lactose-Modified Cellulose Films by a Nonaqueous Enzymatic Reaction and their Biofunctional Characteristics as a Scaffold for Cell Culture, Biomacromolecules, 2009, 10, 1265-1269.

126 B. B. Ke, L. S. Wan, W. X. Zhang and Z. K. Xu, Controlled synthesis of linear and comb-like glycopolymers for preparation of honeycomb-patterned films, Polymer, 2010, 51, 2168-2176.

127 T. T. Kursun, D. Cimen and T. Caykara, Glycopolymer brushes with specific protein recognition property, J. Appl. Polym. Sci., 2017, 134, 45238.

128 N. Behary, A. Perwuelz, C. Campagne, D. Lecouturier, P. Dhulster and A. S. Mamede, Adsorption of surfactin produced from Bacillus subtilis using nonwoven PET (polyethylene terephthalate) fibrous membranes functionalized with chitosan, Colloids Surf., B, 2012, 90, 137-143.

129 F. Y. Mahlicli and S. A. Altinkaya, Surface modification of polysulfone based hemodialysis membranes with layer by layer self assembly of polyethyleneimine/alginate-heparin: a simple polyelectrolyte blend approach for heparin immobilization, J. Mater. Sci.: Mater. Med., 2013, 24, 533-546. 
130 A. P. P. Kroger, M. I. Komil, N. M. Hamelmann, A. Juan, M. H. Stenzel and J. M. J. Paulusse, Glucose Single-Chain Polymer Nanoparticles for Cellular Targeting, ACS Macro Lett., 2019, 8, 95-101.

131 J. Fingernagel, S. Boye, A. Kietz, S. Hobel, K. Wozniak, S. Moreno, A. Janke, A. Lederer, A. Aigner, A. Temme, B. Voit and D. Appelhans, Mono- and Polyassociation Processes of Pentavalent Biotinylated PEI Glycopolymers for the Fabrication of Biohybrid Structures with Targeting Properties, Biomacromolecules, 2019, 20, 3408-3424.

132 H. Zhu, J. Liu, B. Shi, H. Wang, Z. Mao, T. Shan and F. Huang, Pillararene-based host-guest recognition facilitated magnetic separation and enrichment of cell membrane proteins, Mater. Chem. Front., 2018, 2, 1475-1480.

133 M. M. Perez-Madrigal, L. J. del Valle, E. Armelin, C. Michaux, G. Roussel, E. A. Perpete and C. Aleman, Polypyrrolesupported membrane proteins for bio-inspired ion channels, ACS Appl. Mater. Interfaces, 2015, 7, 1632-1643.

134 Y. Liu and H. Vashisth, Conformational dynamics and interfacial interactions of peptide-appended pillar[5]arene water channels in biomimetic membranes, Phys. Chem. Chem. Phys., 2019, 21, 22711-22721.

135 P. Wagh, X. Zhang, R. Blood, P. M. Kekenes-Huskey, P. Rajapaksha, Y. Wei and I. C. Escobar, Increasing Salt Rejection of Polybenzimidazole Nanofiltration Membranes via the Addition of Immobilized and Aligned Aquaporins, Processes, 2019, 7, 76-98.

136 Z. Chen, T. Sun and G. Qing, cAMP-modulated biomimetic ionic nanochannels based on a smart polymer, J. Mater. Chem. B, 2019, 7, 3710-3715.

137 Z. Zhang, P. Li, X. Y. Kong, G. Xie, Y. Qian, Z. Wang, Y. Tian, L. Wen and L. Jiang, Bioinspired Heterogeneous Ion Pump Membranes: Unidirectional Selective Pumping and Controllable Gating Properties Stemming from Asymmetric Ionic Group Distribution, J. Am. Chem. Soc., 2018, 140, 1083-1090.

138 S. Damiati, M. Peacock, R. Mhanna, S. Søpstad, U. B. Sleytr and B. Schuster, Bioinspired detection sensor based on functional nanostructures of S-proteins to target the folate receptors in breast cancer cells, Sens. Actuators, B, 2018, 267, 224-230.

139 M. Kumar, M. Grzelakowski, J. Zilles, M. Clark and W. Meier, Highly permeable polymeric membranes based on the incorporation of the functional water channel protein Aquaporin $\mathrm{Z}$, Proc. Natl. Acad. Sci. U. S. A., 2007, 104, 20719-20724.

140 B. Wager, A. Basle and A. H. Delcour, Disulfide bond tethering of extracellular loops does not affect the closure of OmpF porin at acidic pH, Proteins, 2010, 78, 2886-2894.

141 Q. Sun, M. Radosz and Y. Shen, Challenges in design of translational nanocarriers, J. Controlled Release, 2012, 164, 156-169.

142 Q. Sun, Z. Zhou, N. Qiu and Y. Shen, Rational Design of Cancer Nanomedicine: Nanoproperty Integration and Synchronization, Adv. Mater., 2017, 29, 1606628.

143 R. H. Fang, A. V. Kroll, W. Gao and L. Zhang, Cell Membrane Coating Nanotechnology, Adv. Mater., 2018, 30, 1706759.
144 A. Lejeune, M. Moorjani, C. Gicquaud, J. Lacroix, P. Poyet and R. C. Gaudreault, Nanoerythrosome, a new derivative of erythrocyte ghost: Preparation and antineoplastic potential as drug carrier for daunorubicin, Anticancer Res., 1994, 14, 915-920.

145 Y. Zhai, J. Su, W. Ran, P. Zhang, Q. Yin, Z. Zhang, H. Yu and Y. Li, Preparation and Application of Cell MembraneCamouflaged Nanoparticles for Cancer Therapy, Theranostics, 2017, 7, 2575-2592.

146 D. Sun, J. Chen, Y. Wang, H. Ji, R. Peng, L. Jin and W. Wu, Advances in refunctionalization of erythrocyte-based nanomedicine for enhancing cancer-targeted drug delivery, Theranostics, 2019, 9, 6885-6900.

147 C. M. Hu, L. Zhang, S. Aryal, C. Cheung, R. H. Fang and L. Zhang, Erythrocyte membrane-camouflaged polymeric nanoparticles as a biomimetic delivery platform, Proc. Natl. Acad. Sci. U. S. A., 2011, 108, 10980-10985.

148 C. M. Hu, R. H. Fang, K. C. Wang, B. T. Luk, S. Thamphiwatana, D. Dehaini, P. Nguyen, P. Angsantikul, C. H. Wen, A. V. Kroll, C. Carpenter, M. Ramesh, V. Qu, S. H. Patel, J. Zhu, W. Shi, F. M. Hofman, T. C. Chen, W. Gao, K. Zhang, S. Chien and L. Zhang, Nanoparticle biointerfacing by platelet membrane cloaking, Nature, 2015, 526, 118-121.

149 B. T. Luk, C. M. Hu, R. H. Fang, D. Dehaini, C. Carpenter, W. Gao and L. Zhang, Interfacial interactions between natural RBC membranes and synthetic polymeric nanoparticles, Nanoscale, 2014, 6, 2730-2737.

150 J. Xie, Q. Shen, K. Huang, T. Zheng, L. Cheng, Z. Zhang, Y. Yu, G. Liao, X. Wang and C. Li, Oriented Assembly of Cell-Mimicking Nanoparticles via a Molecular Affinity Strategy for Targeted Drug Delivery, ACS Nano, 2019, 13, 5268-5277.

151 H. Li, K. Jin, M. Luo, X. Wang, X. Zhu, X. Liu, T. Jiang, Q. Zhang, S. Wang and Z. Pang, Size Dependency of Circulation and Biodistribution of Biomimetic Nanoparticles: Red Blood Cell Membrane-Coated Nanoparticles, Cells, 2019, 8, 881-896.

152 W. L. Liu, T. Liu, M. Z. Zou, W. Y. Yu, C. X. Li, Z. Y. He, M. K. Zhang, M. D. Liu, Z. H. Li, J. Feng and X. Z. Zhang, Aggressive Man-Made Red Blood Cells for Hypoxia-Resistant Photodynamic Therapy, Adv. Mater., 2018, 30, 1802006.

153 Y. Guo, D. Wang, Q. Song, T. Wu, X. Zhuang, Y. Bao, M. Kong, Y. Qi, S. Tan and Z. Zhang, Erythrocyte Membrane-Enveloped Polymeric Nanoparticles as Nanovaccine for Induction of Antitumor Immunity against Melanoma, ACS Nano, 2015, 9, 6918-6933.

154 J. Y. Zhu, D. W. Zheng, M. K. Zhang, W. Y. Yu, W. X. Qiu, J. J. Hu, J. Feng and X. Z. Zhang, Preferential Cancer Cell Self-Recognition and Tumor Self-Targeting by Coating Nanoparticles with Homotypic Cancer Cell Membranes, Nano Lett., 2016, 16, 5895-5901.

155 J. Zhu, M. Zhang, D. Zheng, B. Yang, N. Ma, R. Li, J. Feng and X. Zhang, A Biohybrid Lurker-to-Attacker Strategy To Solve Inherent Dilemma of Positively Charged Delivery Nanoparticles, Chem. Mater., 2017, 29, 2227-2231. 
156 J. Y. Zhu, M. K. Zhang, X. G. Ding, W. X. Qiu, W. Y. Yu, J. Feng and X. Z. Zhang, Virus-Inspired Nanogenes Free from Man-Made Materials for Host-Specific Transfection and Bio-Aided MR Imaging, Adv. Mater., 2018, 30, e1707459.

157 W. L. Liu, M. Z. Zou, T. Liu, J. Y. Zeng, X. Li, W. Y. Yu, C. X. Li, J. J. Ye, W. Song, J. Feng and X. Z. Zhang, Expandable Immunotherapeutic Nanoplatforms Engineered from Cytomembranes of Hybrid Cells Derived from Cancer and Dendritic Cells, Adv. Mater., 2019, 31, 1900499.

158 J. T. Parson, K. H. Martin, J. K. Slack, J. M. Taylor and S. A. Weed, Focal Adhesion Kinase: a regulator of focal adhesion dynamics and cell movement, Oncogene, 2000, 19, 5606-5613.

159 E. Zamir and B. Geiger, Molecular complexity and dynamics of cell-matrix adhesions, J. Cell Sci., 2001, 114, 3583-3590.

160 R. O. Hynes, Integrins: Bidirectional, Allosteric Signaling Machines, Cell, 2002, 110, 673-687.

161 X. Yan, Y. Shen and X. Zhu, Live show of Rho GTPases in cell migration, J. Mol. Cell Biol., 2010, 2, 68-69.

162 S. C. Wei and J. Yang, Forcing through Tumor Metastasis: The Interplay between Tissue Rigidity and EpithelialMesenchymal Transition, Trends Cell Biol., 2016, 26, 111-120.

163 Y. Huang, C. Mei, Y. Tian, T. Nie, Z. Liu and T. Chen, Bioinspired tumor-homing nanosystem for precise cancer therapy via reprogramming of tumor-associated macrophages, NPG Asia Mater., 2018, 10, 1002-1015.

164 A. Maruf, Y. Wang, T. Yin, J. Huang, N. Wang, C. Durkan, Y. Tan, W. Wu and G. Wang, Atherosclerosis Treatment with Stimuli-Responsive Nanoagents: Recent Advances and Future Perspectives, Adv. Healthcare Mater., 2019, 8, 1900036.

165 K. Nam, J. Watanabe and K. Ishihara, Modeling of swelling and drug release behavior of spontaneously forming hydrogels composed of phospholipid polymers, Int. J. Pharm., 2004, 275, 259-269.

166 J. P. Xu, J. Ji, W. D. Chen and J. C. Shen, Novel biomimetic polymersomes as polymer therapeutics for drug delivery, J. Controlled Release, 2005, 107, 502-512.

167 M. Ahmed, M. Jawanda, K. Ishihara and R. Narain, Impact of the nature, size and chain topologies of carbohydratephosphorylcholine polymeric gene delivery systems, Biomaterials, 2012, 33, 7858-7870.

168 P. O. Khunsuk, S. Chawalitpong, P. Sawutdeechaikul, T. Palaga and V. P. Hoven, Gold Nanorods Stabilized by Biocompatible and Multifunctional Zwitterionic Copolymer for Synergistic Cancer Therapy, Mol. Pharmaceutics, 2017, 15, 164-174.

169 M. Ukawa, H. Akita, T. Masuda, Y. Hayashi, T. Konno, K. Ishihara and H. Harashima, 2-Methacryloyloxyethyl phosphorylcholine polymer (MPC)-coating improves the transfection activity of GALA-modified lipid nanoparticles by assisting the cellular uptake and intracellular dissociation of plasmid DNA in primary hepatocytes, Biomaterials, 2010, 31, 6355-6362.
170 M. Ahmed, N. Bhuchar, K. Ishihara and R. Narain, Wellcontrolled cationic water-soluble phospholipid polymerDNA nanocomplexes for gene delivery, Bioconjugate Chem., 2011, 22, 1228-1238.

171 S. McRae Page, M. Martorella, S. Parelkar, I. Kosif and T. Emrick, Disulfide cross-linked phosphorylcholine micelles for triggered release of camptothecin, Mol. Pharmaceutics, 2013, 10, 2684-2692.

172 Z. Zhang, Y. Zhou, Z. Zhou, Y. Piao, N. Kalva, X. Liu, J. Tang and Y. Shen, Synthesis of enzyme-responsive phosphoramidate dendrimers for cancer drug delivery, Polym. Chem., 2018, 9, 438-449.

173 Z. Wu, Z. Gan, B. Chen, F. Chen, J. Cao and X. Luo, $\mathrm{pH} /$ redox dual-responsive amphiphilic zwitterionic polymers with a precisely controlled structure as anti-cancer drug carriers, Biomater. Sci., 2019, 7, 3190-3203.

174 Y. Chen, H. Han, H. Tong, T. Chen, H. Wang, J. Ji and Q. Jin, Zwitterionic Phosphorylcholine-TPE Conjugate for pH-Responsive Drug Delivery and AIE Active Imaging, ACS Appl. Mater. Interfaces, 2016, 8, 21185-21192.

175 D. Guo, S. Xu, Y. Huang, H. Jiang, W. Yasen, N. Wang, Y. Su, J. Qian, J. Li, C. Zhang and X. Zhu, Platinum(Iv) complex-based two-in-one polyprodrug for a combinatorial chemo-photodynamic therapy, Biomaterials, 2018, 177, 67-77.

176 X. Yu, Y. Zou, S. Horte, J. Janzen, J. N. Kizhakkedathu and D. E. Brooks, Thermal reversal of polyvalent choline phosphate, a multivalent universal biomembrane adhesive, Biomacromolecules, 2013, 14, 2611-2621.

177 X. Yu, X. Yang, S. Horte, J. N. Kizhakkedathu and D. E. Brooks, A pH and thermosensitive choline phosphatebased delivery platform targeted to the acidic tumor microenvironment, Biomaterials, 2014, 35, 278-286.

178 W. Wang, B. Wang, X. Ma, S. Liu, X. Shang and X. Yu, Tailor-Made pH-Responsive Poly(choline phosphate) Prodrug as a Drug Delivery System for Rapid Cellular Internalization, Biomacromolecules, 2016, 17, 2223-2232.

179 W. Wang, B. Wang, S. Liu, X. Shang, X. Yan, Z. Liu, X. Ma and $\mathrm{X} . \mathrm{Yu}$, Bioreducible Polymer Nanocarrier Based on Multivalent Choline Phosphate for Enhanced Cellular Uptake and Intracellular Delivery of Doxorubicin, ACS Appl. Mater. Interfaces, 2017, 9, 15986-15994.

180 W. l. Wang, X. j. Ma and X. f. Yu, pH-responsive polymersome based on PMCP- $b$-PDPA as a drug delivery system to enhance cellular internalization and intracellular drug release, Chin. J. Polym. Sci., 2017, 35, 1352-1362.

181 P. M. Mclendon, K. M. Fichter and T. M. Reineke, Poly(glycoamidoamine) Vehicles Promote pDNA Uptake through Multiple Routes and Efficient Gene Expression via CaveolaeMediated Endocytosis, Mol. Pharmaceutics, 2010, 7, 738-750.

182 M. Tranter, Y. Liu, S. He, J. Gulick, X. Ren, J. Robbins, W. K. Jones and T. M. Reineke, In vivo delivery of nucleic acids via glycopolymer vehicles affords therapeutic infarct size reduction in vivo, Mol. Ther., 2012, 20, 601-608.

183 D. Wrobel, A. Janaszewska, D. Appelhans, B. Voit, M. Bryszewska and J. Maly, Interactions of dendritic 
glycopolymer with erythrocytes, red blood cell ghosts and membrane enzymes, Int. J. Pharm., 2015, 496, 475-488.

184 L. Zhao, Y. Li, D. Pei, Q. Huang, H. Zhang, Z. Yang, F. Li and T. Shi, Glycopolymers/PEI complexes as serumtolerant vectors for enhanced gene delivery to hepatocytes, Carbohydr. Polym., 2019, 205, 167-175.

185 Y. Liu and J. Li, Advances of cyclodextrin polymers for the delivery of biotech drugs, J. Bioresour. Bioprod., 2016, 1, 7-17.

186 G. Liu, Q. Luo, H. Gao, Y. Chen, X. Wei, H. Dai, Z. Zhang and J. Ji, Cell membrane-inspired polymeric micelles as carriers for drug delivery, Biomater. Sci., 2015, 3, 490-499.

187 A. Dag, P. S. Omurtag Ozgen and S. Atasoy, Glyconanoparticles for Targeted Tumor Therapy of Platinum Anticancer Drug, Biomacromolecules, 2019, 20, 2962-2972.

188 M. Lin, Y. Zhang, G. Chen and M. Jiang, Supramolecular Glyco-nanoparticles Toward Immunological Applications, Small, 2015, 11, 6065-6070.

189 L. Su, W. Zhang, X. Wu, Y. Zhang, X. Chen, G. Liu, G. Chen and M. Jiang, Glycocalyx-Mimicking Nanoparticles for Stimulation and Polarization of Macrophages via Specific Interactions, Small, 2015, 11, 4191-4200.

190 J. Mauris, F. Mantelli, A. M. Woodward, Z. Cao, C. R. Bertozzi, N. Panjwani, K. Godula and P. Argueso, Modulation of ocular surface glycocalyx barrier function by a galectin-3 N-terminal deletion mutant and membrane-anchored synthetic glycopolymers, PLoS One, 2013, 8, e72304.

191 J. Chen, F. Y. Su, D. Das, S. Srinivasan, H. N. Son, B. Lee, F. Radella, 2nd, D. Whittington, T. Monroe-Jones, T. E. West, A. J. Convertine, S. J. Skerrett, P. S. Stayton and D. M. Ratner, Glycan targeted polymeric antibiotic prodrugs for alveolar macrophage infections, Biomaterials, 2019, 195, 38-50.

192 T. Uchiyama, Y. Kiritoshi, J. Watanabe and K. Ishihara, Degradation of phospholipid polymer hydrogel by hydrogen peroxide aiming at insulin release device, Biomaterials, 2003, 24, 5183-5190.

193 W. Liu, C. Deng, C. R. McLaughlin, P. Fagerholm, N. S. Lagali, B. Heyne, J. C. Scaiano, M. A. Watsky, Y. Kato, R. Munger, N. Shinozaki, F. Li and M. Griffith, Collagenphosphorylcholine interpenetrating network hydrogels as corneal substitutes, Biomaterials, 2009, 30, 1551-1559.

194 L. Soletti, A. Nieponice, Y. Hong, S. H. Ye, J. J. Stankus, W. R. Wagner and D. A. Vorp, In vivo performance of a phospholipid-coated bioerodable elastomeric graft for small-diameter vascular applications, J. Biomed. Mater. Res., Part A, 2011, 96, 436-448.

195 Q. Zhong, J. Yan, X. Qian, T. Zhang, Z. Zhang and A. Li, Atomic layer deposition enhanced grafting of phosphorylcholine on stainless steel for intravascular stents, Colloids Surf., B, 2014, 121, 238-247.

196 M. Mirazul Islam, V. Cepla, C. He, J. Edin, T. Rakickas, K. Kobuch, Z. Ruzele, W. Bruce Jackson, M. Rafat, C. P. Lohmann, R. Valiokas and M. Griffith, Functional fabrication of recombinant human collagen-phosphorylcholine hydrogels for regenerative medicine applications, Acta Biomater., 2015, 12, 70-80.
197 N. Zhang, M. A. Melo, C. Chen, J. Liu, M. D. Weir, Y. Bai and $\mathrm{H}$. H. Xu, Development of a multifunctional adhesive system for prevention of root caries and secondary caries, Dent. Mater., 2015, 31, 1119-1131.

198 Y. J. Jin, S. Kang, P. Park, D. Choi, D. W. Kim, D. Jung, J. Koh, J. Jeon, M. Lee, J. Ham, J. H. Seo, H. R. Jin and Y. Lee, Anti-inflammatory and Antibacterial Effects of Covalently Attached Biomembrane-Mimic Polymer Grafts on Gore-Tex Implants, ACS Appl. Mater. Interfaces, 2017, 9, 19161-19175.

199 L. Han, L. Xiang, J. Zhang, J. Chen, J. Liu, B. Yan and H. Zeng, Biomimetic Lubrication and Surface Interactions of Dopamine-Assisted Zwitterionic Polyelectrolyte Coatings, Langmuir, 2018, 34, 11593-11601.

200 W. J. Yang, T. Cai, K. G. Neoh, E. T. Kang, S. L. Teo and D. Rittschof, Barnacle cement as surface anchor for "clicking", of antifouling and antimicrobial polymer brushes on stainless steel, Biomacromolecules, 2013, 14, 2041-2051.

201 Y. Wei, J. X. Zhang, Y. Ji and J. Ji, REDV/Rapamycin-loaded polymer combinations as a coordinated strategy to enhance endothelial cells selectivity for a stent system, Colloids Surf., B, 2015, 136, 1166-1173.

202 D. W. Chen, H. H. Yu, L. J. Luo, S. Rajesh Kumar, C. H. Chen, T. Y. Lin, J. Y. Lai and S. Jessie Lue, Osteoblast Biocompatibility and Antibacterial Effects Using 2-Methacryloyloxyethyl Phosphocholine-Grafted Stainless-Steel Composite for Implant Applications, Nanomaterials, 2019, 9, 939.

203 S. Ghosh, S. Abanteriba, S. Wong, R. Brkljaca and S. Houshyar, Optimisation of grafted phosphorylcholine-based polymer on additively manufactured titanium substrate for hip arthroplasty, Mater. Sci. Eng., C, 2019, 101, 696-706.

204 J. Zhu and R. E. Marchant, Dendritic Saccharide Surfactant Polymers as Antifouling Interface Materials to Reduce Platelet Adhesion, Biomacromolecules, 2006, 7, 1036-1041.

205 T. Wang, S. Zheng, X. Liu, C. Wang, S. Fu and Z. Tong, Spontaneous cell sheet detachment and mechanical performance of nanocomposite hydrogels of poly( $N$-isopropylacrylamide) and Laponite in Dulbecco's Modified Eagle Medium, J. Controlled Release, 2013, 172, e125-e149.

206 A. Chauhan, A. Bernardin, W. Mussard, I. Kriegel, M. Esteve, J. M. Ghigo, C. Beloin and V. Semetey, Preventing biofilm formation and associated occlusion by biomimetic glycocalyxlike polymer in central venous catheters, J. Infect. Dis., 2014, 210, 1347-1356.

207 S. S. Lee, T. Fyrner, F. Chen, Z. Alvarez, E. Sleep, D. S. Chun, J. A. Weiner, R. W. Cook, R. D. Freshman, M. S. Schallmo, K. M. Katchko, A. D. Schneider, J. T. Smith, C. Yun, G. Singh, S. Z. Hashmi, M. T. McClendon, Z. Yu, S. R. Stock, W. K. Hsu, E. L. Hsu and S. I. Stupp, Sulfated glycopeptide nanostructures for multipotent protein activation, Nat. Nanotechnol., 2017, 12, 821-829.

208 U. Hersel, C. Dahmen and H. Kessler, RGD modified polymers: biomaterials for stimulated cell adhesion and beyond, Biomaterials, 2003, 24, 4385-4415.

209 Z. Zhang, Y. Lai, L. Yu and J. Ding, Effects of immobilizing sites of RGD peptides in amphiphilic block copolymers on efficacy of cell adhesion, Biomaterials, 2010, 31, 7873-7882. 
210 P. A. George, B. C. Donose and J. J. Cooper-White, Selfassembling polystyrene-block-poly(ethylene oxide) copolymer surface coatings: resistance to protein and cell adhesion, Biomaterials, 2009, 30, 2449-2456.

211 Y. Xu, M. Takai and K. Ishihara, Protein adsorption and cell adhesion on cationic, neutral, and anionic 2-methacryloyloxyethyl phosphorylcholine copolymer surfaces, Biomaterials, 2009, 30, 4930-4938.

212 Y. Iwasaki, S. Sawada, K. Ishihara, G. Khang and H. B. Lee, Reduction of surface-induced inflammatory reaction on PLGA/MPC polymer blend, Biomaterials, 2002, 23, 3897-3903.

213 J. Watanabe, T. Eriguchi and K. Ishihara, Stereocomplex Formation by Enantiomeric Poly(lactic acid) Graft-Type Phospholipid Polymers for Tissue Engineering, Biomacromolecules, 2002, 3, 1109-1114.

214 J. Watanabe, T. Eriguchi and K. Ishihara, Cell Adhesion and Morphology in Porous Scaffold Based on Enantiomeric Poly(lactic acid) Graft-type Phospholipid Polymers, Biomacromolecules, 2002, 3, 1375-1383.

215 Y. Chen, D. Diaz-Dussan, D. Wu, W. Wang, Y.-Y. Peng, A. B. Asha, D. G. Hall, K. Ishihara and R. Narain, Bioinspired SelfHealing Hydrogel Based on Benzoxaborole-Catechol Dynamic Covalent Chemistry for 3D Cell Encapsulation, ACS Macro Lett., 2018, 7, 904-908.

216 C. Wachiralarpphaithoon, Y. Iwasaki and K. Akiyoshi, Enzyme-degradable phosphorylcholine porous hydrogels cross-linked with polyphosphoesters for cell matrices, Biomaterials, 2007, 28, 984-993.

217 M. He, T. Storr-Paulsen, A. L. Wang, C. E. Ghezzi, S. Wang, M. Fullana, D. Karamichos, T. P. Utheim, R. Islam, M. Griffith, M. M. Islam, R. R. Hodges, G. E. Wnek, D. L. Kaplan and D. A. Dartt, Artificial Polymeric Scaffolds as Extracellular Matrix Substitutes for Autologous Conjunctival Goblet Cell Expansion, Invest. Ophthalmol. Visual Sci., 2016, 57, 6134-6146.

218 X. Chen, T. Chen, Z. Lin, X. E. Li, W. Wu and J. Li, Choline phosphate functionalized surface: protein-resistant but cell-adhesive zwitterionic surface potential for tissue engineering, Chem. Commun., 2015, 51, 487-490.

219 X. Chen, H. Shang, S. Cao, H. Tan and J. Li, A zwitterionic surface with general cell-adhesive and protein-resistant properties, RSC Adv., 2015, 5, 76216-76220.

220 F. Huang, C. Ding and J. Li, Resisting Protein but Promoting Cell Adhesion by Choline Phosphate: A Comparative Study with Phosphorylcholine, J. Bioresour. Bioprod., 2018, 3, 3-8.

221 H. Zhu, J. Ji, R. Lin, C. Gao, L. Feng and J. Shen, Surface engineering of poly(DL-lactic acid) by entrapment of alginate-amino acid derivatives for promotion of chondrogenesis, Biomaterials, 2002, 23, 3141-3148.

222 J. Ji, L. Feng and J. Shen, "Loop” or “Tail”? Self-Assembly and Surface Architecture of Polystyrene-graft- $\omega$-stearylpoly(ethylene oxide), Langmuir, 2003, 19, 2643-2648.

223 R. Liu, D. Patel, H. R. C. Screen and C. R. Becer, A2BMiktoarm Glycopolymer Fibers and Their Interactions with Tenocytes, Bioconjugate Chem., 2017, 28, 1955-1964.
224 R. Liu, C. R. Becer and H. R. C. Screen, Guided Cell Attachment via Aligned Electrospinning of Glycopolymers, Macromol. Biosci., 2018, 18, e1800293.

225 W. Chen, Q. Zhang, B. T. Luk, R. H. Fang, Y. Liu, W. Gao and L. Zhang, Coating nanofiber scaffolds with beta cell membrane to promote cell proliferation and function, Nanoscale, 2016, 8, 10364-10370.

226 H. S. Kojori, Y. Ji, Y. Paik, A. B. Braunschweig and S. J. Kim, Monitoring interfacial lectin binding with nanomolar sensitivity using a plasmon field effect transistor, Nanoscale, 2016, 8, 17357-17364.

227 L. Xue, Z. Lyu, Y. Luan, X. Xiong, J. Pan, G. Chen and H. Chen, Efficient cancer cell capturing SiNWAs prepared via surface-initiated SET-LRP and click chemistry, Polym. Chem., 2015, 6, 3708-3715.

228 C. Zhao, Q. Shi, J. Hou, Z. Xin, J. Jin, C. Li, S.-C. Wong and J. Yin, Efficient cancer cell capturing SiNWAs prepared via surface-initiated SET-LRP and click chemistry, J. Mater. Chem. B, 2016, 4, 4130-4137.

229 H. Park, S. Walta, R. R. Rosencrantz, A. Körner, C. Schulte, L. Elling, W. Richtering and A. Böker, Micelles from selfassembled double-hydrophilic PHEMA-glycopolymer-diblock copolymers as multivalent scaffolds for lectin binding, Polym. Chem., 2016, 7, 878-886.

230 K. Jono, M. Nagao, T. Oh, S. Sonoda, Y. Hoshino and Y. Miura, Controlling the lectin recognition of glycopolymers via distance arrangement of sugar blocks, Chem. Commun., 2017, 54, 82-85.

231 Z. Liu, Y. Zhu, W. Ye, T. Wu, D. Miao, W. Deng and M. Liu, Synthesis of well-defined glycopolymers with highly ordered sugar units in the side chain via combining CuAAC reaction and ROMP: lectin interaction study in homo- and hetero-glycopolymers, Polym. Chem., 2019, 10, 4006-4016.

232 M. Nagao, T. Matsubara, Y. Hoshino, T. Sato and Y. Miura, Synthesis of Various Glycopolymers Bearing Sialyllactose and the Effect of Their Molecular Mobility on Interaction with the Influenza Virus, Biomacromolecules, 2019, 20, 2763-2769.

233 L. Liu, F. Zhou, J. Hu, X. Cheng, W. Zhang, Z. Zhang, G. Chen, N. Zhou and X. Zhu, Topological Glycopolymers as Agglutinator and Inhibitor: Cyclic versus Linear, Macromol. Rapid Commun., 2019, 40, e1900223.

234 Q. Wang, H. Jin, D. Xia, H. Shao, K. Peng, X. Liu, H. Huang, Q. Zhang, J. Guo, Y. Wang, J. Crommen, N. Gan and Z. Jiang, Biomimetic Polymer-Based Method for Selective Capture of C-Reactive Protein in Biological Fluids, ACS Appl. Mater. Interfaces, 2018, 10, 41999-42008.

235 T. Goda, K. Ishihara and Y. Miyahara, Critical update on 2-methacryloyloxyethyl phosphorylcholine (MPC) polymer science, J. Appl. Polym. Sci., 2015, 132, 41766.

236 T. Shimada, T. Yasui, A. Yokoyama, T. Goda, M. Hara, T. Yanagida, N. Kaji, M. Kanai, K. Nagashima, Y. Miyahara, T. Kawai and Y. Baba, Biomolecular recognition on nanowire surfaces modified by the self-assembled monolayer, Lab Chip, 2018, 18, 3225-3229. 
237 P. Akkahat, S. Kiatkamjornwong, S. Yusa, V. P. Hoven and Y. Iwasaki, Development of a novel antifouling platform for biosensing probe immobilization from methacryloyloxyethyl phosphorylcholine-containing copolymer brushes, Langmuir, 2012, 28, 5872-5881.

238 M. Sakono, T. Zako, M. Yohda and M. Maeda, Amyloid oligomer detection by immobilized molecular chaperone, Biochem. Eng. J., 2012, 61, 28-33.

239 L. Song, J. Zhao, J. Jin, J. Ma, J. Liu, S. Luan and J. Yin, Fabricating antigen recognition and anti-bioadhesion polymeric surface via a photografting polymerization strategy, Mater. Sci. Eng., C, 2014, 36, 57-64.

240 K. Wang, X. Fan, X. Zhang, X. Zhang, Y. Chen and Y. Wei, Red fluorescent chitosan nanoparticles grafted with poly(2-methacryloyloxyethyl phosphorylcholine) for live cell imaging, Colloids Surf., B, 2016, 144, 188-195.

241 O. Wiarachai, T. Vilaivan, Y. Iwasaki and V. P. Hoven, Clickable and Antifouling Platform of Poly[(propargyl methacrylate)-ran-(2-methacryloyloxyethyl phosphorylcholine)] for Biosensing Applications, Langmuir, 2016, 32, 1184-1194.

242 Y. Iwasaki, J. I. Kondo, A. Kuzuya and R. Moriyama, Crosslinked duplex DNA nanogels that target specified proteins, Sci. Technol. Adv. Mater., 2016, 17, 285-292.

243 L. Mao, X. Liu, M. Liu, L. Huang, D. Xu, R. Jiang, Q. Huang, Y. Wen, X. Zhang and Y. Wei, Surface grafting of zwitterionic polymers onto dye doped AIE-active luminescent silica nanoparticles through surface-initiated ATRP for biological imaging applications, Appl. Surf. Sci., 2017, 419, 188-196.

244 X. Li, J. Zhou, L. Tian, Y. Wang, B. Zhang, H. Zhang and Q. Zhang, Preparation of anti-nonspecific adsorption polydopamine-based surface protein-imprinted magnetic microspheres with the assistance of 2-methacryloyloxyethyl phosphorylcholine and its application for protein recognition, Sens. Actuators, B, 2017, 241, 413-421.

245 M. Yoshida, K. Hibino, S. Yamamoto, S. Matsumura, Y. Yajima and K. Shiba, Preferential capture of EpCAMexpressing extracellular vesicles on solid surfaces coated with an aptamer-conjugated zwitterionic polymer, Biotechnol. Bioeng., 2018, 115, 536-544.

246 J. J. Liu, J. Yang, J. L. Wang, Z. F. Chang, B. Li, W. T. Song, Z. Zhao, X. Lou, J. Dai and F. Xia, Tetrathienylethene based red aggregation-enhanced emission probes: super red-shifted mechanochromic behavior and highly photostable cell membrane imaging, Mater. Chem. Front., 2018, 2, 1126-1136.

247 Z. Li, L. Wang, Y. Li, Y. Feng and W. Feng, Frontiers in carbon dots: design, properties and applications, Mater. Chem. Front., 2019, 3, 2571-2601.

248 Y. Lv, M. Liu, Y. Zhang, X. Wang, F. Zhang, F. Li, W. E. Bao, J. Wang, Y. Zhang, W. Wei, G. Ma, L. Zhao and Z. Tian, Cancer Cell Membrane-Biomimetic Nanoprobes with Two-Photon Excitation and Near-Infrared Emission for Intravital Tumor Fluorescence Imaging, ACS Nano, 2018, 12, 1350-1358.

249 T. Goda and K. Ishihara, Amyloid oligomer detection by immobilized molecular chaperone, Expert Rev. Med. Devices, 2006, 3, 167-174.

250 A. V. Fuchs, S. Ritz, S. Pütz, V. Mailänder, K. Landfester and $\mathrm{U}$. Ziener, Bioinspired phosphorylcholine containing polymer films with silver nanoparticles combining antifouling and antibacterial properties, Biomater. Sci., 2013, 1, 470-477.

251 Y. Xu, K. Mawatari, T. Konno, T. Kitamori and K. Ishihara, Spontaneous Packaging and Hypothermic Storage of Mammalian Cells with a Cell-Membrane-Mimetic Polymer Hydrogel in a Microchip, ACS Appl. Mater. Interfaces, 2015, 7, 23089-23097.

252 C. Lang, D. Ye, W. Song, C. H. Yao, Y. M. Tu, C. Capparelli, J. A. LaNasa, M. A. Hickner, E. W. Gomez and E. D. Gomez, Biomimetic Separation of Transport and Matrix Functions in Lamellar Block Copolymer Channel-Based Membranes, ACS Nano, 2019, 7, 8292-8302.

253 J. S. Kwon, M. J. Lee, J. Y. Kim, D. Kim, J. H. Ryu, S. Jang, K. M. Kim, C. J. Hwang and S. H. Choi, Novel antibiofouling light-curable fluoride varnish containing 2methacryloyloxyethyl phosphorylcholine to prevent enamel demineralization, Sci. Rep., 2019, 9, 1432.

254 Y. Song, J.-B. Fan and S. Wang, Recent progress in interfacial polymerization, Mater. Chem. Front., 2017, 1, 1028-1040.

255 Y. Iwasaki and K. Ishihara, Cell membrane-inspired phospholipid polymers for developing medical devices with excellent biointerfaces, Sci. Technol. Adv. Mater., 2012, 13, 064101.

256 N. Fujiwara, H. Yumoto, K. Miyamoto, K. Hirota, H. Nakae, S. Tanaka, K. Murakami, Y. Kudo, K. Ozaki and Y. Miyake, 2-Methacryloyloxyethyl phosphorylcholine (MPC)-polymer suppresses an increase of oral bacteria: a single-blind, crossover clinical trial, Clin. Oral Investig., 2019, 23, 739-746. 